\title{
Macroeconomic Interdependence under Incomplete Markets
}

\author{
Fabio Ghironi* \\ Boston College
}

First draft: June 23, 2000

This draft: February 6, 2003

Comments welcome

\begin{abstract}
I develop a tractable, two-country, real model of macroeconomic interdependence with a role for net foreign asset dynamics. Absence of Ricardian equivalence in an overlapping generations structure ensures existence of a well-defined, endogenously determined, steady-state, international distribution of asset holdings, to which the world economy returns following temporary shocks. The model offers a plausible explanation for the failure of statistical tests to reject the hypothesis of a unit root in series of net foreign assets. Model dynamics after productivity shocks are significantly different from those of a setup in which net foreign assets do not move after shocks, such as Corsetti and Pesenti's (2001a) model. The difference relative to a complete markets economy in which net foreign asset movements play no role in shock transmission is smaller. It is amplified if the substitutability across goods rises, if shocks are permanent, and if steady-state net foreign assets are not zero.

Keywords: Current account; Incomplete markets; Net foreign assets; Ricardian equivalence; Stationarity

JEL Classification: F41; G15
\end{abstract}

\section{Introduction}

Many recent open economy models de-emphasize the role of net foreign asset accumulation as a channel of macroeconomic interdependence between countries. This is done either by assuming unitary intratemporal elasticity of substitution between domestic and foreign goods in consumption or by assuming that financial markets are complete (or both). ${ }^{1}$ When the elasticity of substitution between goods produced in two countries is one and purchasing power parity (PPP) holds, the current account does not react to shocks if initial net foreign assets are zero. This is what happens in Corsetti and Pesenti's (2001a) popular model. Complete financial markets, power utility, and

\footnotetext{
${ }^{*}$ Department of Economics, Boston College, Administration Building 473, Chestnut Hill, MA 02467-3806. Phone: (617)552-3686. Fax: (617)552-2308. E-mail: Fabio.Ghironi@bc.edu. URL: http://fmwww.bc.edu/ec/Ghironi.php.

${ }^{1}$ See, for example, Benigno, G. (1999), Benigno, P. (2001a), Benigno and Benigno (2001), Corsetti and Pesenti (2001a, b), Devereux and Engel (2000), Galí and Monacelli (2002), Obstfeld and Rogoff (2000), Tille (2000).
} 
the assumption of zero initial net foreign assets generate similar results also in situations in which PPP does not hold because of local currency pricing. Even if net foreign assets respond to shocks when the elasticity of substitution between domestic and foreign goods differs from one, net foreign asset movements play no role in shock transmission when markets are complete, as the equilibrium allocation is independent of the history of asset accumulation.

Avoiding the well-known stationarity problem of open economy models a la Obstfeld and Rogoff (1995a, 1996 Ch. 10), combined with a quest for tractability, is the main reason why scholars have increasingly adopted frameworks that, de facto, shut off the current account channel of interdependence or relegate it to a secondary role.

The current account plays a crucial role in the transmission of shocks in the original ObstfeldRogoff model, in which each country is populated by a standard representative household with constant discount factor. But the absence of a well defined, endogenously determined steady state makes the conclusions questionable from a theoretical and empirical perspective. The consumption differential between countries follows a random walk. So do an economy's net foreign assets. Whatever level of asset holdings materializes in the period immediately following a shock becomes the new long-run position, until a new shock happens. ${ }^{2}$

Determinacy of the non-stochastic steady state and stationarity fail because the rate of growth of consumption does not depend on holdings of net foreign assets. Hence, setting consumption to be constant is not sufficient to pin down a steady-state distribution of asset holdings. ${ }^{3}$ This makes the choice of the economy's initial position for the purpose of analyzing the consequences of a shock a matter of convenience. When the model is log-linearized, one is approximating its dynamics around a "moving steady state." The results of comparative statics are thus questionable. The reliability of the log-linear approximation is low, especially for analyses with a longer time horizon than just the short run, because variables wander away from the initial steady state. De facto, one cannot perform any sensible stochastic analysis. The inherent unit root problem complicates empirical testing. The long-run non-neutrality of money that characterizes the results can be attacked on empirical grounds. Finally, the presence of a unit root in net foreign assets does not square with the idea of a sustainable foreign debt position in the long run. If net assets can be anywhere with probability 1 in finite time, one is left wondering about debt sustainability.

Scholars soon recognized the problem in Obstfeld and Rogoff's seminal model. Some decided to dismiss it. ${ }^{4}$ Others tried to finesse the current account issue in various ways. Solving the problem

\footnotetext{
${ }^{2}$ The same problem exists in the international real business cycle (RBC) model under incomplete markets puth forth in Baxter and Crucini (1995).

${ }^{3}$ To my knowledge, Becker (1980) was the first to point out the steady-state indeterminacy issue.

${ }^{4}$ Lane and Milesi-Ferretti (2000) use a non-stationary, small open economy model with non-traded goods in their analysis of the transfer problem. See also Duarte and Stockman (2001). Lane (2002) argues that the PPP assumption was the main problem of the Obstfeld-Rogoff model. See Lane (2001) for a survey of the literature.
} 
by setting up models in which accumulation of net foreign assets plays no role (or a secondary one) has become the dominant approach, because it yields theoretically appealing, tractable models.

Nevertheless, the strong assumption of a unitary intratemporal elasticity of substitution between domestic and foreign goods does not help determine the steady-state distribution of net foreign assets in Corsetti and Pesenti (2001a). The choice of the zero equilibrium is dictated only by the fact that, starting from that point, the current account does not react to shocks. The assumption of internationally complete asset markets is not realistic. Obstfeld and Rogoff (2001) review evidence in a number of papers in favor of the result that financial markets are more effective at promoting risk sharing across regions within countries than across countries. ${ }^{5}$

From a positive perspective, the empirical appeal of models in which net foreign assets do not react to shocks, or play no role in shock transmission, appears limited. The recent experience of the United States suggests that the current account indeed plays an important role in the international transmission of shocks. It is commonly argued that the U.S. experienced a favorable shock to productivity relative to the rest of the world in the 1990s. Models in which net foreign assets do not react to shocks cannot explain the recent dynamics of U.S. net foreign assets, nor can they shed light on the possible relation between the productivity shock and the exchange rate of the dollar. ${ }^{6}$ The same models can say nothing about the policy questions that accumulation of large foreign debt poses. ${ }^{7}$

Standard econometric tests would indeed induce one to think that net foreign asset series contain a unit root. Table 1 presents the results of augmented Dickey-Fuller tests for annual and quarterly series of real, per capita net foreign assets for Australia, Canada, France, Germany, Italy, Japan, New Zealand, the U.K., and the U.S. The sample covers the period 1973-1997.

Letting $B$ denote aggregate per capita, real net foreign assets, the test adjusts for the presence of a trend in the data by running the regression:

$$
\Delta \log B_{t}=\delta \log B_{t-1}+\alpha_{1}+\alpha_{2} t+\sum_{i=1}^{s} \kappa_{i} \Delta \log B_{t-i}+\text { error }_{t}
$$

\footnotetext{
${ }^{5}$ See Asdrubali, Sørensen, and Yosha (1996), Atkeson and Bayoumi (1993), Bayoumi and Klein (1997), Crucini (1999), and Sørensen and Yosha (1998). Obstfeld and Rogoff (1995a, 1996 Ch. 10) also argue that the complete markets assumption appears incongruous next to that of sticky prices.

${ }^{6}$ One could reasonably argue that the productivity shock caused the U.S. to borrow from the rest of the world and that the capital inflow resulted in the observed exchange rate appreciation. See Cavallo and Ghironi (2002) on this.

${ }^{7}$ It is sometimes argued that allowing net foreign asset accumulation to play a role is not necessary in models that are used to answer normative questions because accumulation of net foreign assets has a second-order effect on welfare. I address welfare issues in work currently in progress.

${ }^{8}$ Net foreign asset data came from the dataset constructed by Philip Lane and Gian Maria Milesi-Ferretti, available at http://econserv2.bess.tcd.ie/plane. The series of cumulated current account balances (CUMCA) was used for all countries. Quarterly series were constructed by interpolating annual data.
} 
where $\Delta$ denotes the first-difference operator. As Table 1 shows, we can reject the null of a unit root in net foreign assets $\left(H_{0}: \delta=0\right)$ at the 5 percent confidence level only for Australia at quarterly frequency. 9

Taken at face value, the test suggests that a unit root is a common feature of net foreign asset dynamics. But judging from the fact that most scholars have rejected the idea of working with models in which assets are non-stationary, this failure to reject a unit root (even after adjusting for a trend) raises questions more than it lends clear support to non-stationary models.

A possible interpretation of the results in Table 1 is that the power of unit root tests such as that performed above on relatively short data series is limited. ${ }^{10}$ If the tendency of net foreign assets to return to a long-run, stationary equilibrium after non-permanent real shocks is very slow, unit root tests on relatively short series will invariably fail to detect it and to reject the hypothesis of a unit root. The requirement of sustainability of net asset positions suggests that some sort of stationary, long-run equilibrium (possibly different from zero) should exist for a country's net foreign assets. Empirical evidence suggests that the tendency of net assets to return to this equilibrium is likely to be very slow. Thus, the question is whether we can reconcile theoretical modeling of macroeconomic interdependence with empirical evidence and sustainability issues in an easily quantifiable way.

In this paper, I address this question and the model stationarity issue by developing a tractable, two-country, real model of macroeconomic interdependence in which the elasticity of substitution between domestic and foreign goods can differ from one and financial markets are incomplete. ${ }^{11}$ Absence of Ricardian equivalence in an overlapping generations structure as that used by Weil in a series of papers ensures existence of a well-defined, endogenously determined, steady-state distribution of asset holdings across countries, to which the world economy returns following nonpermanent shocks. (See Weil, 1987, 1989a,b, and 1991. Henceforth, I will refer to Weil's work without mentioning publication years, except when I am referencing a specific paper.) In this setup, accumulation of net foreign assets plays a role in the transmission of shocks to productivity.

The model matches the very slow tendency of assets to return to the steady state that one expects from the data for very plausible parameter values. The force that generates long-run stationarity and slow return of assets to the steady state after shocks (entry of new households with no assets in each period) is easily quantifiable. The behavior of each individual household in the economy is isomorphic to that of the representative household of the Obstfeld-Rogoff modeland of mainstream macroeconomics. These are distinct advantages over alternative solutions to

\footnotetext{
${ }^{9}$ If $B_{t}<0$ at any time during the sample, the entire series was rescaled to $B_{t}+\underline{B}+1$ before taking logs, where $\underline{B}$ is the absolute value of the largest negative realization of $B_{t}$.

${ }^{10}$ See Hamilton (1994) for a comprehensive treatment of the topic.

${ }^{11}$ There is no money nor nominal rigidity or monetary policy in the model, as this is not central to the analysis.
} 
the stationarity issue under incomplete markets, which I discuss below.

In the spirit of Baxter and Crucini's (1995) two-country analysis and Schmitt-Grohé and Uribe's (2003) recent small open economy exercise, I compare model dynamics after country-specific productivity shocks to those of the benchmark models of the recent literature on macroeconomic interdependence, namely, the Corsetti-Pesenti (2001a) setup and the complete markets with zero initial net foreign assets model. For completeness, the comparison includes also the non-stationary case and a case in which net foreign assets return to the steady state unrealistically quickly. I find that models that rely on the Corsetti-Pesenti assumption of unitary elasticity of substitution between domestic and foreign goods can miss quantitatively significant features of shock transmission dynamics after non-permanent shocks if the true value of the elasticity of substitution differs from 1. The difference relative to a complete markets benchmark in which net foreign assets play no role in shock transmission is smaller. A similar conclusion holds with respect to the non-stationary, incomplete markets case or the fast convergence one, especially over the first two-three years after a shock. The comparison with the complete markets benchmark, the non-stationary economy, and the case of fast convergence is roughly consistent with Baxter and Crucini's comparison of complete markets and a non-stationary, incomplete markets economy and Schmitt-Grohé and Uribe's findings for the small open economy case if the true elasticity of substitution between domestic and foreign goods is not very different from $1 .{ }^{12}$ Differences across specifications are more significant if the substitutability between domestic and foreign goods rises. This can generate arguably non-negligible differences in dynamics over the short and medium term, in contrast to Schmitt-Grohé and Uribe's findings. The small open economy of their model produces and consumes the same good as the rest of the world. Similarly, both countries produce and consume the same good in Baxter and Crucini's model. This prevents Baxter and Crucini and Schmitt-Grohé and Uribe from analyzing the consequences of changes in the extent to which domestic and foreign goods are substitutable. More importantly, it removes terms of trade dynamics from the model. I find that terms of trade movements are important to generate differences across incomplete markets specifications. As in Baxter and Crucini's article, the difference between incomplete and complete markets is amplified substantially if productivity shocks are permanent. Finally, the difference between the incomplete markets economy of this paper and the complete markets, zero initial wealth benchmark in the case of non-permanent shocks is more significant if steady-state net foreign assets are not zero in the

\footnotetext{
${ }^{12}$ Although the difference between impulse responses generated by the stationary and non-stationary incomplete markets models is small over the short and medium term, it would be incorrect to question the relevance of the model non-stationarity issue. The difference amplifies with the passing of time. Most importantly, the unconditional variances of net foreign assets, consumption, and other endogenous variables are infinite in the non-stationary model, even if exogenous shocks are bounded. Even if I focus on a perfect foresight environment in this paper, it is clear that stochastic simulation of non-stationary open economy models makes little sense. This is not the case for stationary models.
} 
incomplete markets economy, consistent with evidence in Lane and Milesi-Ferretti (2001, 2002a, $b)$.

The structure of the paper is as follows. Section 2 presents the model. Section 3 derives the steady state and illustrates the role of the departure from Ricardian equivalence. Section 4 solves the log-linear model and analyzes the role of asset accumulation. Section 5 concludes.

\section{The Model}

The world consists of two countries, home and foreign. In each period $t$, the world economy is populated by a continuum of infinitely lived households between 0 and $N_{t}^{W}$. Each household consumes, supplies labor, and holds financial assets. Following Weil, I assume that households are born on different dates owning no assets, but they own the present discounted value of their labor income. ${ }^{13}$ The number of households in the home economy, $N_{t}$, grows over time at the exogenous rate $n$, i.e., $N_{t+1}=(1+n) N_{t}$. I normalize the size of a household to 1 , so that the number of households alive at each point in time is the economy's population. Foreign population $\left(N_{t}^{*}\right)$ grows at the same rate as home population. The world economy has existed since the infinite past. It is useful to normalize world population at time 0 so that $N_{0}^{W}=1$.

At time 0 , the number of goods that are supplied in the world economy is equal to the number of households. A continuum of goods $z \in[0,1]$ are produced in the world by monopolistically competitive, infinitely lived firms, each producing a single differentiated good. The number of households grows over time, but the commodity space remains unchanged. Thus, as time goes, the ownership of firms spreads across a larger number of households. Profits are distributed to consumers via dividends, and the structure of the market for each good is taken as given. I assume that the domestic economy produces goods in the interval $[0, a]$, which is also the size of the home population at time 0 , whereas the foreign economy produces goods in the range $(a, 1] .{ }^{14}$

The asset menu includes a riskless real bond denominated in units of the world consumption basket and shares in firms. Private agents in both countries trade the real bond domestically and internationally. I assume that shares in home (foreign) firms are held only by home (foreign) residents to ensure diversity of asset portfolios across agents born in the same period in different countries.

\footnotetext{
${ }^{13}$ Blanchard (1985) combines this assumption with a positive probability of not surviving until the next period.

${ }^{14}$ The assumption of monopolistic competition in the market for individual goods is not central to the results of this paper. Because the equilibrium of the model will be such that profits are zero in all periods, monopolistic competition could be replaced with competitive product markets without altering any important result. I retain the assumption of monopolistic competition as it facilitates the extension of the model to the case of sticky prices, in which profits are different from zero when the economy is not in steady state.
} 


\subsection{Consumers}

Agents have perfect foresight, though they can be surprised by initial unexpected shocks. Consumers have identical preferences over a real consumption index $(C)$ and leisure $(1-L$, where I normalize the endowment of time in each period to 1 , and $L$ is labor effort supplied in a competitive labor market). At any time $t_{0}$, the representative home consumer $j$ born in period $v \in\left[-\infty, t_{0}\right]$ maximizes the intertemporal utility function:

$$
U_{t_{0}}^{v^{j}}=\sum_{t=t_{0}}^{\infty} \beta^{t-t_{0}}\left[\rho \log C_{t}^{v^{j}}+(1-\rho) \log \left(1-L_{t}^{v^{j}}\right)\right]
$$

with $0<\beta<1$ and $0<\rho<1$. $^{15}$

The consumption index for the representative domestic consumer is:

$$
C_{t}^{v^{j}}=\left[a^{\frac{1}{\omega}}\left(C_{H t}^{v^{j}}\right)^{\frac{\omega-1}{\omega}}+(1-a)^{\frac{1}{\omega}}\left(C_{F t}^{v^{j}}\right)^{\frac{\omega-1}{\omega}}\right]^{\frac{\omega}{\omega-1}}
$$

where $\omega>0$ is the intratemporal elasticity of substitution between domestic and foreign goods. ${ }^{16}$ The consumption sub-indexes that aggregate individual domestic and foreign goods are, respectively:

$$
C_{H t}^{v^{j}}=\left[\left(\frac{1}{a}\right)^{\frac{1}{\theta}} \int_{0}^{a}\left(c_{t}^{v^{j}}(i)\right)^{\frac{\theta-1}{\theta}} d i\right]^{\frac{\theta}{\theta-1}} \quad \text { and } \quad C_{F t}^{v^{j}}=\left[\left(\frac{1}{1-a}\right)^{\frac{1}{\theta}} \int_{a}^{1}\left(c_{* t}^{v^{j}}(i)\right)^{\frac{\theta-1}{\theta}} d i\right]^{\frac{\theta}{\theta-1}},
$$

where $c_{* t}^{v^{j}}(i)$ denotes time $t$ consumption of good $i$ produced in the foreign country, and $\theta>1$ is the elasticity of substitution between goods produced inside each country. ${ }^{17}$

The representative home consumer enters a period holding bonds and shares purchased in the previous period. He or she receives interests and dividends on these assets, may earn capital gains or incur losses on shares, earns labor income, and consumes.

Denote the date $t$ price (in units of the world consumption basket) of a claim to the representative domestic firm $i$ 's entire future profits (starting on date $t+1$ ) by $V_{t}^{i}$, and let $x_{t+1}^{v^{j i}}$ be the share of the representative domestic firm $i$ owned by the representative domestic consumer $j$ born in period $v$ at the end of period $t . d_{t}^{i}$ denotes the real dividends that firm $i$ pays on date $t$

\footnotetext{
${ }^{15}$ This is a special case of an isoelastic function of a Cobb-Douglas composite of consumption and leisure in which the intertemporal elasticity of substitution has been set to one. Results do not change in the more general case in which the elasticity differs from one. Foreign agents maximize an identical function and are subject to similar constraints.

${ }^{16}$ For the sake of simplicity, I often refer to the representative member of generation $v$ as the "representative consumer." Strictly speaking, though, the model I set up is not a representative consumer one, as representative agents of different generations may behave differently.

${ }^{17}$ Foreign agents consume an identical basket of goods. Trade in goods is free and each individual good has an identical real price in the two economies.
} 
(in units of consumption). Then, letting $B_{t+1}^{v^{j}}$ be the representative home consumer's holdings of bonds entering $t+1$, the period budget constraint is:

$$
\begin{aligned}
& B_{t+1}^{v^{j}}+\int_{0}^{a}\left(V_{t}^{i} x_{t+1}^{v^{j i}}-V_{t-1}^{i} x_{t}^{v^{j i}}\right) d i \\
= & \left(1+r_{t}\right) B_{t}^{v^{j}}+\int_{0}^{a} d_{t}^{i} x_{t}^{v^{j i}} d i+\int_{0}^{a}\left(V_{t}^{i}-V_{t-1}^{i}\right) x_{t}^{v^{j i}} d i+w_{t} L_{t}^{v^{j}}-C_{t}^{v^{j}},
\end{aligned}
$$

where $r_{t}$ is the world real interest rate between $t-1$ and $t$ and $w_{t}$ is the real wage, both in units of the consumption basket. ${ }^{18}$

The representative domestic consumer born in period $v$ maximizes the intertemporal utility function (1) subject to the constraint (2). Dropping the $j$ superscript (because symmetric agents make identical choices in equilibrium), optimal labor supply is given by:

$$
L_{t}^{v}=1-\frac{1-\rho}{\rho} \frac{C_{t}^{v}}{w_{t}}
$$

which equates the marginal cost of supplying labor to the marginal utility of consumption generated by the corresponding increase in labor income.

The first-order condition for optimal holdings of bonds yields the Euler equation:

$$
C_{t}^{v}=\frac{1}{\beta\left(1+r_{t+1}\right)} C_{t+1}^{v}
$$

for all $v \leq t$.

Absence of arbitrage opportunities between bonds and shares requires:

$$
1+r_{t+1}=\frac{d_{t+1}^{i}+V_{t+1}^{i}}{V_{t}^{i}}
$$

As usual, first-order conditions and the period budget constraint must be combined with appropriate transversality conditions to ensure optimality. ${ }^{19}$

\section{$2.2 \quad$ Firms}

Output supplied at time $t$ by the representative domestic firm $i$ is a linear function of labor demanded by the firm: ${ }^{20}$

$$
Y_{t}^{\mathrm{Si}}=Z_{t} L_{t}^{i}
$$

\footnotetext{
${ }^{18}$ Given that individuals are born owning no financial wealth, because they are not linked by altruism to individuals born in previous periods, $B_{v}^{v^{j}}=x_{v}^{v^{j i}}=0$. As noted before, however, individuals are born owning the present discounted value of their labor income. Foreign agents are subject to a similar period budget constraint.

${ }^{19}$ Similar labor-leisure tradeoff, Euler equation, no-arbitrage, and transversality conditions hold for foreign agents.

${ }^{20}$ Because all firms in the world economy are born at $t=-\infty$, after which no new goods appear, it is not necessary to index output and factor demands by the firms' date of birth. I do not include capital in the production function to keep the model simple, as the main purpose of this paper is to illustrate the mechanics of the setup rather than to match specific features of business cycle fluctuations in actual economies. See Ghironi (2000) for an extension of the model to include investment in physical capital in the small open economy case.
} 
$Z_{t}$ is exogenous economy-wide productivity. Production by the representative foreign firm is a linear function of $L_{t}^{i *}$, with productivity $Z_{t}^{*}$.

Output demand comes from domestic and foreign consumers. The demand of home good $i$ by the representative domestic household born in period $v$ is:

$$
c_{t}^{v}(i)=\left(R P_{t}^{i}\right)^{-\theta}\left(R P_{t}\right)^{\theta-\omega} C_{t}^{v},
$$

obtained by maximizing $C$ subject to a spending constraint. $R P_{t}^{i}$ is the price of good $i$ in units of the composite consumption basket. $R P_{t}$ is the price of the sub-basket of home goods in units of consumption. Total demand for home good $i$ coming from domestic consumers is:

$$
\begin{gathered}
c_{t}(i)=a\left[\begin{array}{c}
\cdots \frac{n}{(1+n)^{t+1}} c_{t}^{-t}(i)+\ldots+\frac{n}{(1+n)^{2}} c_{t}^{-1}(i)+\frac{n}{1+n} c_{t}^{0}(i) \\
+n c_{t}^{1}(i)+n(1+n) c_{t}^{2}(i)+\cdots+n(1+n)^{t-1} c_{t}^{t}(i)
\end{array}\right]= \\
\left(R P_{t}^{i}\right)^{-\theta}\left(R P_{t}\right)^{\theta-\omega} a\left[\begin{array}{c}
\ldots \frac{n}{(1+n)^{t+1}} C_{t}^{-t}+\ldots+\frac{n}{(1+n)^{2}} C_{t}^{-1}+\frac{n}{1+n} C_{t}^{0} \\
+n C_{t}^{1}+n(1+n) C_{t}^{2}+\cdots+n(1+n)^{t-1} C_{t}^{t}
\end{array}\right]= \\
\left(R P_{t}^{i}\right)^{-\theta}\left(R P_{t}\right)^{\theta-\omega} a(1+n)^{t} c_{t},
\end{gathered}
$$

where

$$
c_{t} \equiv \frac{a\left[\begin{array}{c}
\cdots \frac{n}{(1+n)^{t+1}} C_{t}^{-t}+\ldots+\frac{n}{(1+n)^{2}} C_{t}^{-1}+\frac{n}{1+n} C_{t}^{0} \\
+n C_{t}^{1}+n(1+n) C_{t}^{2}+\cdots+n(1+n)^{t-1} C_{t}^{t}
\end{array}\right]}{a(1+n)^{t}}
$$

is aggregate per capita home consumption of the composite consumption basket. ${ }^{21}$

Given identity of preferences across countries, total demand for home good $i$ by foreign consumers is

$$
c_{t}^{*}(i)=\left(R P_{t}^{i}\right)^{-\theta}\left(R P_{t}\right)^{\theta-\omega}(1-a)(1+n)^{t} c_{t}^{*},
$$

where

$$
c_{t}^{*} \equiv \frac{(1-a)\left[\begin{array}{c}
\cdots \frac{n}{(1+n)^{t+1}} C_{t}^{-t^{*}}+\ldots+\frac{n}{(1+n)^{2}} C_{t}^{-1^{*}}+\frac{n}{1+n} C_{t}^{0^{*}} \\
+n C_{t}^{1^{*}}+n(1+n) C_{t}^{2^{*}}+\cdots+n(1+n)^{t-1} C_{t}^{t^{*}}
\end{array}\right]}{(1-a)(1+n)^{t}}
$$

\footnotetext{
${ }^{21}$ At time 0 , home population is equal to $a$. At time 1 , it is $a(1+n)$. Hence, generation 1 consists of an households. Population at time 2 is $a(1+n)^{2}$. It follows that generation 2 consists of $a n(1+n)$ households. Continuing with this reasoning shows that generation $t$ consists of an $(1+n)^{t-1}$ households. Going back in time from $t=0$, home population at time -1 is $\frac{a}{1+n}$. Hence, generation 0 consists of $\frac{a n}{1+n}$ households. Population at time -2 is $\frac{a}{(1+n)^{2}}$. It follows that generation -1 consists of $\frac{a n}{(1+n)^{2}}$ households. Continuing with this reasoning shows that generation $-t$ consists of $\frac{a n}{(1+n)^{t+1}}$ households.
} 
is aggregate per capita foreign consumption.

Total demand for good $i$ produced in the home country is obtained by adding the demands for that good originating in the two countries. Making use of the results above, it is:

$$
Y_{t}^{D i}=\left(R P_{t}^{i}\right)^{-\theta}\left(R P_{t}\right)^{\theta-\omega} \widehat{c}_{t}^{W}
$$

where $\widehat{c}_{t}^{W}$ is aggregate world demand of the composite good: $\widehat{c}_{t}^{W} \equiv N_{t} c_{t}+N_{t}^{*} c_{t}^{*}{ }^{22}$

Given the no-arbitrage condition between bonds and shares (5) and a no-speculative bubble condition, the real price of firm $i$ 's shares at time $t_{0}$ is given by the present discounted value of the real dividends paid by the firm from $t_{0}+1$ on: $V_{t_{0}}^{i}=\sum_{s=t_{0}+1}^{\infty} R_{t_{0}, s} d_{s}^{i}$, where $R_{t_{0}, s} \equiv$ $\left[\prod_{u=t_{0}+1}^{s}\left(1+r_{u}\right)\right]^{-1}, R_{t_{0}, t_{0}}=1$. At time $t_{0}$, firm $i$ maximizes the present discounted value of dividends to be paid from $t_{0}$ on: $V_{t_{0}}^{i}+d_{t_{0}}^{i}=\sum_{s=t_{0}}^{\infty} R_{t_{0}, s} d_{s}^{i}$. At each point in time, dividends are given by after-tax real revenues- $(1-\tau) R P_{t}^{i} Y_{t}^{i}$-plus a lump-sum transfer (or tax) from the government$T_{t}^{i}$-minus costs $-w_{t} L_{t}^{i}$. The firm chooses the real price of its product and the amount of labor demanded to maximize the present discounted value of its current and future profits subject to the constraints (6), (7), and the market clearing condition $Y_{t}^{\mathrm{Si}}=Y_{t}^{D i}\left(=Y_{t}^{i}\right)$. Firm $i$ takes the real price of the sub-basket of home goods, the wage rate, productivity, the rate of taxation of revenues $(\tau)$, the transfer received from the government, and world demand of the composite good as given.

Let $\lambda_{t}^{i}$ denote the Lagrange multiplier on the constraint $Y_{t}^{\mathrm{Si}}=Y_{t}^{D i} . \lambda_{t}^{i}$ is the shadow price of an extra unit of output in period $t$. The first-order condition for the optimal choice of $L_{t}^{i}$ yields:

$$
\lambda_{t}=\frac{w_{t}}{Z_{t}} .
$$

At an optimum, the shadow value of output must equal marginal cost. The $i$ superscript has been dropped because symmetric firms make identical choices in equilibrium.

The first-order condition with respect to $R P_{t}^{i}$ yields the pricing equation:

$$
R P_{t}^{i}=R P_{t}=\frac{\theta}{(\theta-1)(1-\tau)} \lambda_{t}
$$

which equates the price charged by firm $i$ to a markup over marginal cost. Identical equilibrium choices by symmetric firms imply that the real price of good $i$ equals the real price of the sub-basket of home goods in equilibrium.

Using the market clearing conditions $Y_{t}^{\mathrm{Si}}=Y_{t}^{D i}$ and $\widehat{c}_{t}^{W}=\widehat{Y}_{t}^{S W}=\widehat{Y}_{t}^{D W}\left(=\widehat{Y}_{t}^{W}\right)$, the expressions for supply and demand of good $i$, and recalling that symmetric firms make identical

\footnotetext{
${ }^{22}$ Where necessary for clarity, I make use of a "hat" to differentiate the aggregate level of a variable from the aggregate per capita level.
} 
equilibrium choices, labor demand can be written as:

$$
L_{t}^{i}=R P_{t}^{-\omega} \frac{\widehat{Y}_{t}^{W}}{Z_{t}}
$$

Ceteris paribus, firm $i$ 's labor demand is a decreasing function of real output price and productivity. It is an increasing function of world consumption demand. ${ }^{23}$

\subsection{The Government}

The government's only role in the economy consists of taxing firm revenues and rebating tax income to firms via lump-sum transfers. I assume that the government taxes revenues at a rate that compensates for monopoly power and removes the markup charged by firms over marginal costs in equilibrium. The tax rate is determined by $1-\tau=\frac{\theta}{\theta-1}$, which yields $\tau=-\frac{1}{\theta-1}$. Because the tax rate is negative, firms receive a subsidy on their revenues and pay lump-sum taxes determined by:

$$
T_{t}^{i}=\tau R P_{t}^{i} Y_{t}^{i}
$$

\subsection{Aggregation}

\subsubsection{Consumers}

Aggregate per capita labor supply equations are obtained by aggregating labor-leisure tradeoff equations across generations and dividing by total population at each point in time. The aggregate per capita labor-leisure tradeoffs in the two economies are:

$$
L_{t}=1-\frac{1-\rho}{\rho} \frac{c_{t}}{w_{t}}, \quad L_{t}^{*}=1-\frac{1-\rho}{\rho} \frac{c_{t}^{*}}{w_{t}^{*}} .
$$

Aggregate labor supply rises with the real wage and decreases with consumption.

Consumption Euler equations in aggregate per capita terms contain an adjustment for consumption by the newborn generation at time $t+1$. As we shall see, this adjustment plays an important role in the model's stationarity. It is: ${ }^{24}$

$$
c_{t}=\frac{1+n}{\beta\left(1+r_{t+1}\right)}\left(c_{t+1}-\frac{n}{1+n} C_{t+1}^{t+1}\right), \quad c_{t}^{*}=\frac{1+n}{\beta\left(1+r_{t+1}\right)}\left(c_{t+1}^{*}-\frac{n}{1+n} C_{t+1}^{t+1 *}\right) .
$$

\footnotetext{
${ }^{23}$ Although all domestic firms demand the same amount of labor in equilibrium, I leave the $i$ superscript on labor demand to differentiate labor employed by an individual firm from aggregate per capita employment, which will be denoted by dropping the superscript. Optimality conditions for foreign firms are similar.

${ }^{24}$ To understand the presence of $C_{t+1}^{t+1}$ in the aggregate Euler equation, apply the aggregation formula to both sides of the Euler equation $C_{t}^{v}=\frac{1}{\beta\left(1+r_{t+1}\right)} C_{t+1}^{v}$. It is:

$$
\frac{a\left[\begin{array}{c}
\cdots \frac{n}{(1+n)^{t+1}} C_{t}^{-t}+\ldots+\frac{n}{1+n} C_{t}^{0} \\
+n C_{t}^{1}+\cdots+n(1+n)^{t-1} C_{t}^{t}
\end{array}\right]}{a(1+n)^{t}}=\frac{1}{\beta\left(1+r_{t+1}\right)} \frac{a\left[\begin{array}{c}
\cdots \frac{n}{1+n)^{t+1}} C_{t+1}^{-t}+\ldots+\frac{n}{1+n} C_{t+1}^{0} \\
+n C_{t+1}^{1}+\cdots+n(1+n)^{t-1} C_{t+1}^{t}
\end{array}\right]}{a(1+n)^{t}} .
$$

The left-hand side of this equation is equal to $c_{t}$. The right-hand side is $\frac{1}{\beta\left(1+r_{t+1}\right)}\left[(1+n) c_{t+1}-n C_{t+1}^{t+1}\right]$.
} 
Newborn households hold no assets, but they own the present discounted value of their labor income. Using the Euler equation (4) and a newborn household's intertemporal budget constraint, it is possible to show that the household's consumption in the first period of its life is a fraction of its human wealth, $h$ :

$$
C_{t}^{t}=\rho(1-\beta) h_{t}, \quad C_{t}^{t *}=\rho(1-\beta) h_{t}^{*}
$$

$h$ and $h^{*}$ are defined as the present discounted values of the households' lifetime endowments of time in terms of the real wages, respectively: ${ }^{25}$

$$
h_{t} \equiv \sum_{s=t}^{+\infty} R_{t, s} w_{s}, \quad h_{t}^{*} \equiv \sum_{s=t}^{+\infty} R_{t, s} w_{s}^{*} .
$$

The dynamics of $h$ and $h^{*}$ are described by the following forward-looking difference equations:

$$
h_{t}=\frac{h_{t+1}}{1+r_{t+1}}+w_{t}, \quad h_{t}^{*}=\frac{h_{t+1}^{*}}{1+r_{t+1}}+w_{t}^{*} .
$$

The law of motion of aggregate per capita assets held by domestic consumers is obtained by aggregating the budget constraint (2) across generations alive at each point in time. Using the no-arbitrage condition (5) and recalling that newborn agents hold no assets, aggregate per capita assets of domestic and foreign consumers obey, respectively:

$$
\begin{aligned}
(1+n)\left(B_{t+1}+V_{t}\right) & =\left(1+r_{t}\right)\left(B_{t}+V_{t-1}\right)+w_{t} L_{t}-c_{t} \\
(1+n)\left(B_{t+1}^{*}+V_{t}^{*}\right) & =\left(1+r_{t}\right)\left(B_{t}^{*}+V_{t-1}^{*}\right)+w_{t}^{*} L_{t}^{*}-c_{t}^{*}
\end{aligned}
$$

where $V_{t}$ and $V_{t}^{*}$ denote the aggregate per capita equity value of the home and foreign economies entering period $t+1$, respectively $\left(V_{t} \equiv \frac{a V_{t}^{i}}{N_{t+1}}, V_{t}^{*} \equiv \frac{a V_{t}^{* i}}{N_{t+1}^{*}}\right) \cdot{ }^{26}$

To explain the adjustment for population growth that appears on the left-hand side of these equations, consider aggregation of bond holdings in the home economy. When the aggregation formula is applied to both sides of the individual household's budget constraint, $B_{t}$ results from aggregation of bond holdings on the right-hand side. At the left-hand side, we have:

$$
\frac{a\left[\begin{array}{c}
\ldots \frac{n}{(1+n)^{t+1}} B_{t+1}^{-t}+\ldots+\frac{n}{(1+n)^{2}} B_{t+1}^{-1}+\frac{n}{1+n} B_{t+1}^{0} \\
+n B_{t+1}^{1}+n(1+n) B_{t+1}^{2}+\ldots+n(1+n)^{t-1} B_{t+1}^{t}
\end{array}\right]}{a(1+n)^{t}} .
$$

\footnotetext{
${ }^{25}$ Blanchard (1985) defines human wealth as the present discounted value of future, exogenous noninterest income. Weil defines human wealth as the present discounted value of after-tax endowment income. Labor income is endogenous in this paper. The definition of human wealth as the present discounted value of an agent's exogenous endowment of time parallels those of Blanchard and Weil.

${ }^{26}$ In general, these equations hold in all periods following the initial one. The no arbitrage condition between bonds and shares may be violated ex post between time $t_{0}-1$ and $t_{0}$ if an unexpected shock surprises agents at the beginning of period $t_{0}$. Appendix A shows that this issue does not pose problems in this paper.
} 
This is different from $B_{t+1}$. However, because newborn agents have no financial assets, $B_{t+1}^{t+1}=0$, and this expression can be rewritten as:

$$
(1+n) \frac{a\left[\begin{array}{c}
\ldots \frac{n}{(1+n)^{t+1}} B_{t+1}^{-t}+\ldots+\frac{n}{(1+n)^{2}} B_{t+1}^{-1}+\frac{n}{1+n} B_{t+1}^{0} \\
+n B_{t+1}^{1}+\ldots+n(1+n)^{t-1} B_{t+1}^{t}+n(1+n)^{t} B_{t+1}^{t+1}
\end{array}\right]}{a(1+n)^{t+1}}=(1+n) B_{t+1} .
$$

\subsubsection{Firms}

Aggregate per capita output in each economy is obtained by expressing production of each differentiated good in units of the composite basket, multiplying by the number of firms, and dividing by population. It is:

$$
y_{t}=R P_{t} Z_{t} L_{t}, \quad y_{t}^{*}=R P_{t}^{*} Z_{t}^{*} L_{t}^{*}
$$

For given employment and productivity, each country's real GDP rises with the relative price of the representative good produced in that country, as this is worth more units of the consumption basket.

Aggregate per capita labor demand is:

$$
L_{t}=R P_{t}^{-\omega} \frac{y_{t}^{W}}{Z_{t}}, \quad L_{t}^{*}=R P_{t}^{*-\omega} \frac{y_{t}^{W}}{Z_{t}^{*}}
$$

where $y_{t}^{W}$ is aggregate per capita world production of the composite good, equal to aggregate per capita world consumption, $c_{t}^{W}$. It is $y_{t}^{W}=a y_{t}+(1-a) y_{t}^{*}$ and $c_{t}^{W}=a c_{t}+(1-a) c_{t}^{*} ; y_{t}^{W}=c_{t}^{W}$ to ensure market clearing.

Domestic and foreign relative prices are equal to marginal costs, because government subsidies remove the effect of the monopolistic distortion on pricing in equilibrium: ${ }^{27}$

$$
R P_{t}=\frac{w_{t}}{Z_{t}}, \quad R P_{t}^{*}=\frac{w_{t}^{*}}{Z_{t}^{*}}
$$

Shares are a liability in the balance sheets of firms. In the absence of arbitrage opportunities between bonds and shares, the aggregate per capita equity value of the home and foreign economies entering period $t+1$ must evolve according to:

$$
V_{t}=\frac{1+n}{1+r_{t+1}} V_{t+1}+\frac{d_{t+1}}{1+r_{t+1}}, \quad V_{t}^{*}=\frac{1+n}{1+r_{t+1}} V_{t+1}^{*}+\frac{d_{t+1}^{*}}{1+r_{t+1}} .
$$

where $d_{t}$ and $d_{t}^{*}$ denote aggregate per capita dividends, equal to $(1-\tau) y_{t}+T_{t}-w_{t} L_{t}$ and $\left(1-\tau^{*}\right) y_{t}^{*}+T_{t}^{*}-w_{t}^{*} L_{t}^{*}$, respectively $\left(\tau=\tau^{*}\right)$.

\footnotetext{
${ }^{27}$ This has no impact on the log-linear model. Firms charge a constant markup, the effect of which would disappear in the linearized version. The presence of the subsidy simplifies the solution for the steady state.
} 


\subsubsection{Government}

The government budget constraint in aggregate per capita terms is:

$$
T_{t}=\tau y_{t}, \quad T_{t}^{*}=\tau^{*} y_{t}^{*}
$$

\subsubsection{Net Foreign Asset Accumulation}

Each country's accumulation of net foreign assets is described by an equation that combines the budget constraints of households, the fact that shares are liabilities of firms towards consumers in the respective economy, and the government budget constraints. In aggregate per capita terms, it is:

$$
(1+n) B_{t+1}=\left(1+r_{t}\right) B_{t}+y_{t}-c_{t}, \quad(1+n) B_{t+1}^{*}=\left(1+r_{t}\right) B_{t}^{*}+y_{t}^{*}-c_{t}^{*}
$$

For asset markets to be in equilibrium, aggregate home assets (liabilities) must equal aggregate foreign liabilities (assets), i.e., it must be $\widehat{B}_{t}+\widehat{B}_{t}^{*}=0$. In aggregate per capita terms, it must be:

$$
a B_{t}+(1-a) B_{t}^{*}=0
$$

Using (23), equations (22) reduce to $y_{t}^{W}=c_{t}^{W}$ : Consistent with Walras' Law, asset market equilibrium implies goods market equilibrium, and vice versa.

\section{The Steady State}

\subsection{Indeterminacy of the Steady State and Non-Stationarity in a Representa- tive Agent Framework}

Suppose $n=0$. The model reduces to a familiar representative agent framework. Asset accumulation in the home country is described by: ${ }^{28}$

$$
B_{t+1}=\left(1+r_{t}\right) B_{t}+y_{t}-c_{t}
$$

The consumption Euler equation has the familiar form:

$$
c_{t}=\frac{1}{\beta\left(1+r_{t+1}\right)} c_{t+1} .
$$

Using the Euler equation and the intertemporal version of the home country budget constraint (24) yields the consumption function:

$$
c_{t}=(1-\beta)\left[\left(1+r_{t}\right) B_{t}+\sum_{s=t}^{+\infty} R_{t, s} y_{s}\right] .
$$

\footnotetext{
${ }^{28}$ I omit equations for the foreign economy. They are identical to those for home, except for variables being starred.
} 
Thus, asset accumulation can be written as:

$$
B_{t+1}=\beta\left(1+r_{t}\right) B_{t}+y_{t}-(1-\beta) \sum_{s=t}^{+\infty} R_{t, s} y_{s}
$$

Similarly for $B_{t+1}^{*}$, subject to the constraint $a B_{t}+(1-a) B_{t}^{*}=0$. The steady-state version of $(26)$ is:

$$
\bar{B}[1-\beta(1+\bar{r})]=\bar{y}\left[1-(1-\beta) \frac{1+\bar{r}}{\bar{r}}\right] .
$$

Similarly for $\bar{B}^{*}$, with $a \bar{B}+(1-a) \bar{B}^{*}=0$. (Overbars denote steady-state levels.)

Now, consumption must be constant in steady state. For this to happen, the steady-state real interest rate $\bar{r}$ must be determined by $\beta(1+\bar{r})=1$. But if we set $\bar{r}=\frac{1-\beta}{\beta}$ in equation (27) and in its foreign counterpart, we see immediately that the steady-state levels of asset holdings $(\bar{B}$ and $\left.\bar{B}^{*}\right)$ and real output $\left(\bar{y}\right.$ and $\left.\bar{y}^{*}\right)$ remain indeterminate.

In addition, if we take the ratio of equation (25) and its foreign counterpart, we have:

$$
\frac{c_{t}}{c_{t}^{*}}=\frac{c_{t+1}}{c_{t+1}^{*}}
$$

In logs, the consumption differential between the two economies is a random walk. Any shock that changes the consumption differential today has permanent consequences. This happens because, under incomplete markets-and thus imperfect "risk-sharing"-given an initial (arbitrary) choice for the international distribution of asset holdings, (asymmetric) shocks cause the distribution to change permanently by generating initial differences in the behavior of consumption and output.

The representative agent model does not determine the steady-state distribution of asset holdings because consumption growth in the Euler equation does not depend on the country's holdings of net foreign assets. Hence, when consumption is set to be constant, nothing pins down an international allocation of bond holdings. This is the result originally obtained by Becker (1980). All this changes once $n \neq 0$ and new agents with no assets enter the economy at each point in time.

\subsection{Population Growth and Ricardian (In)Equivalence}

\subsubsection{Determinacy of the Steady State}

When $n$ is different from zero and new agents with no assets are born on each date, consumption Euler equations in aggregate per capita terms include consumption by the newborn generation at time $t+1$ in the first period of its life (equations (13)). The law of motion for aggregate per capita net foreign assets is adjusted for population growth. Because households are born with no assets, their consumption in the first period of life is a function only of their human wealth 
(equations (14)). But this is also the variable that determines a generation's initial choice of asset accumulation. Hence, a link is introduced between aggregate per capita consumption growth and asset accumulation. The link operates through the discrepancy between assets of agents already alive at each point in time and assets of newborn agents (zero). It is through this link that a steady-state distribution of aggregate per capita net foreign assets is determined endogenously in the model.

If a structure of transfers across generations were in place, such that all generations (including newborn ones) were characterized by equal asset holdings, the model would reduce to a representative agent framework, subject to the indeterminacy discussed above. Non-stationarity would follow: The consequences of temporary shocks would be transmitted across generations through the intergenerational transfer of assets rather than dying out as a consequence of the birth of an increasing number of agents with no assets. ${ }^{29}$ A small departure from Ricardian equivalence-captured in the model by a rate of birth of agents with no assets $(n)$ that can be very small-is sufficient to solve the problem. This is entirely consistent with the empirical debate on Ricardian equivalence.

To see the mechanism at work, consider the home economy, and set aggregate per capita consumption to be constant. It is:

$$
\bar{c}\left[1-\frac{\beta(1+\bar{r})}{1+n}\right]=\frac{n}{1+n} \bar{C}_{v}^{v}
$$

where $\bar{C}_{v}^{v}$ is steady-state consumption by a newborn generation in the first period of its life. Assume $\frac{\beta(1+\bar{r})}{1+n}<1$ to ensure that steady-state consumption is positive. As we shall see, this assumption is automatically satisfied as long as $n>0$.

From equation (14) and the definition of $h, \bar{C}_{v}^{v}$ is:

$$
\bar{C}_{v}^{v}=\rho(1-\beta) \frac{1+\bar{r}}{\bar{r}} \bar{w} .
$$

Hence, aggregate per capita consumption as a function of the steady-state real wage and interest rate is:

$$
\bar{c}=\frac{n \rho(1-\beta)(1+\bar{r})}{\bar{r}[1+n-\beta(1+\bar{r})]} \bar{w} .
$$

Under the assumption that $\bar{Z}=1$, steady-state GDP is:

$$
\bar{y}=\overline{R P} \bar{L}
$$

From the pricing equation,

$$
\overline{R P}=\bar{w},
$$

\footnotetext{
${ }^{29}$ The same would be true if agents cared about the welfare of their offsprings and internalized their future budget constraints.
} 
because the monopolistic distortion is removed by the subsidy $\tau$. It follows that:

$$
\bar{y}=\bar{w} \bar{L}
$$

From the labor-leisure tradeoff, it is:

$$
\bar{L}=1-\frac{1-\rho}{\rho} \frac{\bar{c}}{\bar{w}}
$$

Using equations (30), (33), (34), and a steady-state version of the law of motion for home's net foreign assets yields:

$$
\bar{B}=\frac{1}{\bar{r}-n}\left\{\frac{n(1-\beta)(1+\bar{r})-\bar{r}[1+n-\beta(1+\bar{r})]}{\bar{r}[1+n-\beta(1+\bar{r})]}\right\} \bar{w} .
$$

Similarly, foreign steady-state assets are given by

$$
\bar{B}^{*}=\frac{1}{\bar{r}-n}\left\{\frac{n(1-\beta)(1+\bar{r})-\bar{r}[1+n-\beta(1+\bar{r})]}{\bar{r}[1+n-\beta(1+\bar{r})]}\right\} \bar{w}^{*} .
$$

Substituting equations (35) and (36) in the asset market equilibrium condition, $a \bar{B}+(1-a) \bar{B}^{*}=$ 0 , yields:

$$
\frac{1}{\bar{r}-n}\left\{\frac{n(1-\beta)(1+\bar{r})-\bar{r}[1+n-\beta(1+\bar{r})]}{\bar{r}[1+n-\beta(1+\bar{r})]}\right\}\left[a \bar{w}+(1-a) \bar{w}^{*}\right]=0 .
$$

Given non-zero real wages at home and abroad, the only admissible level of the interest rate that satisfies the market clearing condition is such that $\beta(1+\bar{r})=1$, or

$$
\bar{r}=\frac{1-\beta}{\beta} .
$$

Substituting this result into equations (35) and (36) yields steady-state levels of domestic and foreign net foreign assets $\bar{B}=\bar{B}^{*}=0$. Consistent with the fact that the two economies are structurally symmetric in per capita terms, the long-run net foreign asset position is zero. Differently from Baxter and Crucini (1995), Obstfeld and Rogoff (1995a, 1996 Ch. 10), and others, this position is pinned down endogenously by the model.

Given the level of the interest rate in (37), steady-state consumption becomes $\bar{c}=\rho \bar{w}$. Hence, from equation (34), it follows immediately that $\bar{L}=\rho$. (Similarly, $\bar{c}^{*}=\rho \bar{w}^{*}$, and the foreign labor-leisure tradeoff implies $\bar{L}^{*}=\rho$.) Steady-state aggregate per capita employment is vertical in the (real wage, employment) space. It is determined by the relative importance of consumption and leisure in utility. The more important consumption, the more labor is supplied to generate income that is necessary to finance consumption. From $\bar{y}=\overline{R P} \rho=\bar{w} \rho$ and $\bar{y}^{*}=\overline{R P}^{*} \rho=\bar{w}^{*} \rho$, we have $\frac{\bar{y}}{\bar{y}^{*}}=\frac{\bar{w}}{\bar{w}^{*}}$. Steady-state labor demands are: $\bar{L}=\overline{R P}^{-\omega} \bar{y}^{W}=\bar{w}^{-\omega} \bar{y}^{W}$ and $\bar{L}^{*}=\overline{R P}^{*-\omega} \bar{y}^{W}=$ 
$\bar{w}^{*-\omega} \bar{y}^{W}$. Imposing labor market clearing and taking the ratio of these equations shows that steady-state real wages (and relative prices) are equal in the two countries: $\bar{w}=\bar{w}^{*}$, which implies that consumption and GDP levels are equalized as well (consistent with zero net foreign assets in equilibrium).

To complete the solution for the steady state, we need to determine the level of the real wage. From the previous results, $\bar{y}=\bar{c}=\bar{y}^{*}=\bar{c}^{*}=\bar{y}^{W}=\bar{c}^{W}$. Hence, labor demand at home can be written as $\bar{L}=\bar{w}^{-\omega} \bar{c}$. Imposing labor market clearing and using $\bar{c}=\rho \bar{w}$ makes it possible to conclude that $\bar{w}=1\left(=\bar{w}^{*}\right)$ if $\omega \neq 1$. (If $\omega=1$, steady-state real wages and relative prices are pinned down by the fact that $\overline{R P}=\overline{R P}^{*}$ implies a unitary value of the steady-state terms of trade between home and foreign-the ratio $\frac{\overline{R P}}{\overline{R P}}$. In this case, one can verify that a Cobb-Douglas consumption basket of the form $C=\frac{C_{H}^{a} C_{F}^{1-a}}{a^{a}(1-a)^{1-a}}$ implies $\overline{R P}=\overline{R P}^{*}=1=\bar{w}=\bar{w}^{*}$.) Thus, consumption equals employment in steady state: In the absence of financial assets, it is optimal to have equal consumption and effort levels, given that labor is transformed into consumption goods at a unitary rate. ${ }^{30}$

To summarize the characteristics of the steady state, it is:

$$
\begin{aligned}
\bar{B} & =\bar{B}^{*}=0, \quad \bar{r}=\frac{1-\beta}{\beta}, \quad \bar{w}=\overline{R P}=\bar{w}^{*}=\overline{R P}^{*}=1, \quad \bar{h}=\bar{h}^{*}=\frac{1}{1-\beta}, \\
\bar{y} & =\bar{c}=\bar{C}_{v}^{v}=\bar{L}=\bar{y}^{*}=\bar{c}^{*}=\bar{C}_{v}^{v *}=\bar{L}^{*}=\bar{y}^{W}=\bar{c}^{W}=\rho .
\end{aligned}
$$

\subsubsection{Stationarity: A Preliminary Discussion}

The steady state described above is taken as the initial position of the world economy for the purpose of analyzing the consequences of shocks. The analysis of the log-linear equations that govern the model's dynamics in a neighborhood of the steady state will show that the model is stationary as long as $n>0$ and productivity shocks are not permanent: Following temporary shocks, aggregate per capita variables return to the long-run position above. This sub-section provides a preliminary discussion of stationarity in the non-linear case.

Letting $A_{t+1}^{v}$ denote assets (including shares in firms) held by the representative household born in period $v$ at the beginning of time $t+1$, the household's intertemporal budget constraint is: ${ }^{31}$

$$
\sum_{s=t}^{+\infty} R_{t, s} C_{s}^{v}=\left(1+r_{t}\right) A_{t}^{v}+\sum_{s=t}^{+\infty} R_{t, s} w_{s} L_{s}^{v}
$$

\footnotetext{
${ }^{30}$ In steady state, a newborn household's consumption is also equal to $\rho$. Because $\beta(1+\bar{r})=1$, the household's consumption remains constant at that level as long as the economy is in steady state.

${ }^{31}$ I have used the equilibrium period budget constraint for dates following an initial shock and the no-arbitrage condition between bonds and shares in deriving this intertemporal budget constraint.
} 
Using the Euler equation for the household's consumption and the labor-leisure tradeoff, it is easy to show that the household's consumption of composite good and leisure (evaluated in units of consumption) is a fraction of the household's resources over its remaining lifetime (assets, interest income, and the real value of the remaining life span):

$$
C_{t}^{v}+w_{t}\left(1-L_{t}^{v}\right)=(1-\beta)\left[\left(1+r_{t}\right) A_{t}^{v}+\sum_{s=t}^{+\infty} R_{t, s} w_{s}\right] .
$$

Aggregating this consumption function across generations and recalling the definition of $h$ yields:

$$
c_{t}+w_{t}\left(1-L_{t}\right)=(1-\beta)\left[\left(1+r_{t}\right) A_{t}+h_{t}\right]
$$

Now, households' aggregate per capita assets entering period $t+1$ are the sum of net foreign bond holdings and the equity value of the home economy: $A_{t+1}=B_{t+1}+V_{t}$. But aggregate per capita dividends are zero at all points in time in equilibrium: $d_{t}=y_{t}-w_{t} L_{t}, y_{t}=R P_{t} Z_{t} L_{t}$, and $R P_{t}=\frac{w_{t}}{Z_{t}}$ imply $d_{t}=0 .{ }^{32}$ This is intuitive: Labor is the only factor of production, and the monopolistic distortion is removed by the government subsidy. All income generated by production is distributed to labor. The dynamics of the aggregate per capita equity value of the home economy are described by the difference equation $V_{t}=\frac{1+n}{1+r_{t+1}} V_{t+1}+\frac{d_{t+1}}{1+r_{t+1}}$. In the absence of speculative bubbles, it follows that $V_{t}=0 \forall t$ in equilibrium. Hence, equation (39) can be rewritten as:

$$
c_{t}+w_{t}\left(1-L_{t}\right)=(1-\beta)\left[\left(1+r_{t}\right) B_{t}+h_{t}\right]
$$

and taking the home aggregate per capita labor-leisure tradeoff in (12) into account yields the aggregate per capita consumption function:

$$
c_{t}=\rho(1-\beta)\left[\left(1+r_{t}\right) B_{t}+h_{t}\right] .
$$

Foreign aggregate per capita consumption obeys a similar equation. In each period, countries consume a fraction of their asset holdings (principal and interest income) and of their human wealths.

Because dividends are zero, $y_{t}=w_{t} L_{t}$ in equilibrium. Therefore, using the labor-leisure tradeoff and the consumption function (40) returns:

$$
y_{t}=w_{t}-(1-\beta)(1-\rho)\left[\left(1+r_{t}\right) B_{t}+h_{t}\right] .
$$

\footnotetext{
${ }^{32}$ Because $T_{t}=\tau y_{t}$, it is $d_{t}=(1-\tau) y_{t}+T_{t}-w_{t} L_{t}=y_{t}-w_{t} L_{t}$.
} 
Substituting equations (40) and (41) into the law of motion for domestic aggregate per capita net foreign assets in (22) and recalling the definition of $h_{t}$ yields:

$$
B_{t+1}=\frac{\beta\left(1+r_{t}\right)}{1+n} B_{t}+\frac{w_{t}-(1-\beta) \sum_{s=t}^{+\infty} R_{t, s} w_{s}}{1+n} .
$$

Equation (42) describes aggregate per capita accumulation of net foreign assets as a function of the paths of the world real interest rate and of the real wage. A similar equation holds for foreign net foreign assets. Showing stationarity of the non-linear model requires determining the paths of domestic and foreign real wages (in particular, of $h$ and $h^{*}$ ) as a function of assets as well as the path of the world interest rate. Non-linearity of labor demand makes it hard to proceed analytically. Nevertheless, intuition can be gained from the partial equilibrium analysis of a small open economy version of the model along the lines of Obstfeld and Rogoff (1996 Ch. 3.7).

Suppose $a$ is sufficiently close to 0 that the home economy has a negligible impact on foreign. The world interest rate is determined only as a function of foreign variables. Suppose further that the foreign economy is in steady state, so that the world interest rate is constant: $r_{t}=r \forall t$. Allow temporarily for structural asymmetries between home and foreign, so that $r$ may differ from $\bar{r}$ such that $\beta(1+\bar{r})=1$. If the domestic real wage is constant $\left(w_{t}=\bar{w}\right)$, equation (42) reduces to:

$$
B_{t+1}=\frac{\beta(1+r)}{1+n} B_{t}+\frac{\beta(1+r)-1}{r(1+n)} \bar{w}
$$

If $\frac{\beta(1+r)}{1+n}<1$, net foreign assets converge to the steady-state level $\frac{\beta(1+r)-1}{r[1+n-\beta(1+r)]} \bar{w}$ starting from any initial position. The intuition is simple. Suppose an unexpected, temporary shock caused the economy to move to a position that differs from the steady state. Eventually, entry of new households with no assets in each period at a rate such that $\frac{\beta(1+r)}{1+n}<1$ "wipes out" the consequences of the shock on aggregate per capita net foreign assets. ${ }^{33}$ In turn, convergence of net foreign assets to the steady state ensures stationarity of the economy.

The World Interest Rate Equation (42) and its foreign counterpart yield an equation for the determination of the world interest rate in the two-country, general equilibrium world. Multiplying equation (42) by $a$ and its foreign counterpart by $1-a$, adding the resulting equations, and recalling the asset market equilibrium condition (23) yields:

$$
w_{t}^{W}=(1-\beta) h_{t}^{W} .
$$

\footnotetext{
${ }^{33}$ If the steady-state world real interest rate is such that $\beta(1+r)=1$ (as it is in the general equilibrium, twocountry model of this paper), the condition $\frac{\beta(1+r)}{1+n}<1$ is automatically satisfied as long as $n>0$ and net foreign assets converge to $\bar{B}=0$.
} 
However, from the equations for $h$ and $h^{*}$, it must also be the case that:

$$
h_{t}^{W}=\frac{h_{t+1}^{W}}{1+r_{t+1}}+w_{t}^{W}
$$

Equations (43) and (44) yield the following equation for the world interest rate:

$$
1+r_{t+1}=\frac{w_{t+1}^{W}}{\beta w_{t}^{W}}
$$

The real interest rate between $t$ and $t+1$ reflects world-wide growth in real wages between those two periods, adjusted for the discount factor.

\subsection{Antecedents and Alternative Approaches}

In the Introduction, I discussed two possible ways to circumvent the issue of indeterminacy of the steady state and non-stationarity, by assuming unitary intratemporal elasticity of substitution between domestic and foreign goods in consumption and/or complete asset markets. These assumptions appear to dominate the recent literature, at least in what some call "new open economy macroeconomics." As I mentioned, they amount to shutting off the current account channel of interdependence or relegating it to a secondary role in many scenarios. Here, I discuss other approaches to the problem.

Buiter (1981) is the first antecedent to my approach. He shows that an overlapping generations model with finite lifetimes can deliver a determinate, non-degenerate distribution of asset holdings across countries. Frenkel and Razin (1987) develop a model of macroeconomic interdependence that relies on Blanchard's (1985) assumption that agents face a non-zero probability of dying at each point in time along with entry of new households with no assets in each period. ${ }^{34}$ When agents die, their assets are transferred to insurance companies that cover their outstanding debts. Frenkel and Razin use the Blanchard demographic structure "to conduct a meaningful analysis of budget deficits in the absence of distortions" (p. 311) rather than with the explicit purpose of generating stationary dynamics for their open economy model. (They use the departure from Ricardian equivalence implied by Blanchard's structure to make the timing of taxes and spending matter.) However, it turns out that Blanchard's structure works much in the same way as Weil's in generating steady-state determinacy-the main difference being the inclusion of a probability of death. (Extending the Weil setup to Blanchard's would be a matter of relatively straightforward algebra, but it would add little to the main point of this paper.) Weil (1989b) uses a continuoustime version of the setup in this paper, with exogenous endowment income that is identical across

\footnotetext{
${ }^{34}$ See also Yaari (1965).
} 
generations, to generalize Buiter's (1981) results. ${ }^{35}$ Cardia (1991) uses the Blanchard framework in her small open economy model. A discussion of some properties of the Weil structure in a discrete-time, small open economy model with exogenous interest rate and labor income can be found in Obstfeld and Rogoff $(1995 b, 1996 \mathrm{Ch}$. 3.7). I generalized it to a model with nominal rigidity, markup pricing, capital accumulation, and endogenous labor supply in Ghironi (1999, 2000). ${ }^{36}$ More recently, Smets and Wouters (2002) rely on the Blanchard specification in a small open economy setup. The contribution of this paper in relation to this literature is to show the implications of the Weil assumption and clarify the functioning of the model in a discrete-time, two-country, general equilibrium environment with endogenous labor income that is in line with the recent literature in international macroeconomics, yet more tractable than models that are built with the explicit purpose of matching business cycle features of actual economies.

Other scholars have pursued different ways to generate determinacy and stationarity, which do not rely on changes in the dynamics of population. Correia, Neves, and Rebelo (1995) develop a representative agent model of a small open economy in which a stable steady state exists for employment and the ratios capital/employment, consumption/capital, and net foreign assets/capital. The approach pursued here has the advantage of generating a steady state for variables that are directly relevant for normative analysis. ${ }^{37}$ Mendoza (1991) and Obstfeld (1990) obtain stationarity by assuming that the rate of time preference depends on consumption and, through this, on net foreign assets, an approach originally proposed by Uzawa (1968) and initially introduced in continuous-time, open economy models by Obstfeld $(1981 a, b)$. Corsetti, Dedola, and Leduc (2002), Kim and Kose (2003), and McDonald and Guest (2001) are recent examples of the same approach. Smets and Wouters (1999) assume that agents derive utility from asset holdings. Heathcote and Perri (2002) and Neumeyer and Perri (1999) introduce a cost of bond holdings in the consumers' period budget constraint. Benigno, P. (2001b) makes a similar assumption. Kollmann (2002) and Schmitt-Grohé and Uribe (2001) obtain stationarity of their small open economy models by assuming that the interest rate at which the home economy can borrow internationally is given by the world interest rate plus a premium that increases in the country's stock of foreign debt. All these assumptions ensure that the equilibrium rate of consumption growth depends on asset holdings, so that setting consumption to be constant pins down a steady-state distribution of net foreign assets. They all yield tractable models, which avoid some of the complications of the framework developed here. Nonetheless, on one side, the gain in terms of tractability is limited: All

\footnotetext{
${ }^{35}$ In Weil $(1989 b)$, it is exchange rate indeterminacy a la Kareken and Wallace (1981) that results in indeterminacy of the current account. Exchange rate indeterminacy is not a relevant issue here. It can be resolved in monetary versions of the model by designing monetary policy at home and abroad appropriately.

${ }^{36}$ See also Devereux (2003).

${ }^{37}$ Stationary dynamics of these variables ensure that their second moments are well defined, which facilitates welfare evaluation.
} 
models mentioned above are solved by numerical methods. On the other side, assumptions about the functional form of the discount factor, utility from asset holdings, cost of bond holdings, or the determination of the interest premium appear more $a d$ hoc and harder to quantify on empirical grounds than assuming that a small number of households with no assets enter the economy in each period. In the Weil-world of this paper, each individual household in the economy behaves as the representative agent of the original Obstfeld-Rogoff setup. Aggregate per capita assets are stationary, individual household's are not. ${ }^{38}$

In a recent paper, Schmitt-Grohé and Uribe (2003) compare five different versions of the small open economy model (Uzawa preferences, cost of portfolio adjustment, debt elastic premium, standard non-stationary setup, complete markets) and conclude that all models deliver similar dynamics at business cycle frequencies (though consumption is smoother under complete markets) when they are parameterized to match the behavior of the Canadian economy. This finding is somewhat unsurprising, at least as far as stationary, incomplete markets models are concerned. Different solutions to non-stationarity under incomplete markets should deliver similar results if they are parameterized to match a given economy. There is no presumption for it to be otherwise. The similarity of results across the stationary, incomplete markets results, the non-stationary model, and the complete markets world is more striking. ${ }^{39}$ There are several possible explanations. Canadian net foreign assets are a relatively small fraction of GDP. Since stationarity or non-stationarity matter through changes in net foreign assets, model parameterizations to match an economy where net foreign assets are a small fraction of GDP are bound to generate similar results. We shall see that, in the model of this paper, with zero steady-state net foreign assets, the small size of elasticities of endogenous variables to net foreign assets implied by plausible parameter values causes the paths of consumption after non-permanent shocks to be fairly close to those of a non-stationary version, the Corsetti-Pesenti model, or a complete markets setup (though the latter is somewhat smoother). This is in line with Schmitt-Grohé and Uribe's findings (and with those of other studies, including Baxter and Crucini, 1995). Yet, the dynamics of labor effort and GDP delivered by the Corsetti-Pesenti model are quite different from those of the alternatives. Thus, if the true elasticity of substitution between domestic and foreign goods differs from 1, approximating it with this value may miss important features of business cycle transmission. In addition, we shall

\footnotetext{
${ }^{38}$ Searching for a determinate non-stochastic steady state is not the only approach to macroeconomic interdependence under incomplete markets. Ljungqvist and Sargent (2000) describe a number of models in which a stationary equilibrium is defined in terms of a stationary probability distribution of asset-holdings/state-of-nature pairs. They discuss conditions under which this distribution exists and is unique. Clarida (1990) and Devereux and Saito (1997) use a similar approach. However, this is different from the more traditional approach in international business cycle analysis, which typically starts from the linearization (or higher order approximation) of the model around a deterministic steady state.

${ }^{39}$ Though supported also by results in Baxter and Crucini (1995), Chari, Kehoe, and McGrattan (2002), Heathcote and Perri (2002), and Kehoe and Perri (2002).
} 
see that the difference between complete and incomplete markets increases with substitutability between goods and shock persistence.

\section{Dynamics: The Role of Asset Accumulation}

The model of Section 3 can be safely log-linearized around the steady state. From here on, sansserif variables denote percentage deviations from the steady-state levels obtained in the previous section. As usual, it is convenient to solve the log-linearized model for cross-country differences $\left(\mathrm{x}_{t}^{D} \equiv \mathrm{x}_{t}-\mathrm{x}_{t}^{*}\right.$ for any pair of variables $\mathrm{x}$ and $\left.\mathrm{x}^{*}\right)$ and world aggregates $\left(\mathrm{x}_{t}^{W} \equiv a \mathrm{x}_{t}+(1-a) \mathrm{x}_{t}^{*}\right)$. Solutions for individual country variables can be recovered easily from those for differences and world aggregates.

\subsection{Country Differences}

In log-linear terms, the difference between domestic and foreign relative prices equals the difference between real wages adjusted by relative productivity:

$$
\mathrm{RP}_{t}^{D}=\mathrm{w}_{t}^{D}-\mathrm{Z}_{t}^{D}
$$

$\mathrm{RP}^{D}$ is also the terms of trade of the home economy-the price of the representative home good in units of the representative foreign good.

Relative employment is:

$$
\mathrm{L}_{t}^{D}=-\omega \mathrm{RP}_{t}^{D}-\mathrm{Z}_{t}^{D}=-\omega \mathrm{w}_{t}^{D}+(\omega-1) \mathrm{Z}_{t}^{D}
$$

A higher real wage differential is associated with higher real prices in the home economy and lower employment. The impact of productivity depends on $\omega$. For given wage differential, if the elasticity of substitution between domestic and foreign goods is larger (smaller) than one, a larger domestic productivity than foreign raises (lowers) domestic employment relative to foreign because it lowers relative prices more (less) than it causes employment to decrease directly. If $\omega=1$, productivity affects relative employment only through its impact on the wage differential (if any): $\mathrm{L}_{t}^{D}=-\mathrm{w}_{t}^{D}$.

Relative GDP is:

$$
\mathrm{y}_{t}^{D}=\mathrm{RP}_{t}^{D}+\mathrm{L}_{t}^{D}+\mathrm{Z}_{t}^{D}=-(\omega-1)\left(\mathrm{w}_{t}^{D}-\mathrm{Z}_{t}^{D}\right) .
$$

World demand has no impact on the output differential, because it affects domestic and foreign output equally. If $\omega>1(\omega<1)$, a domestic productivity advantage raises (lowers) output for

given real wage. When $\omega=1$, domestic and foreign real outputs are equal regardless of relative productivity: $\mathrm{y}_{t}=\mathrm{y}_{t}^{*}$. 
The labor-leisure tradeoffs in (12) determine the real wage differential as a function of consumption and employment differentials:

$$
\mathrm{w}_{t}^{D}=\mathrm{c}_{t}^{D}+\frac{\rho}{1-\rho} \mathrm{L}_{t}^{D}
$$

The real wage is positively related to consumption and employment.

Combining (47) and (49) yields:

$$
\mathrm{L}_{t}^{D}=-\frac{1-\rho}{1+\rho(\omega-1)}\left[\omega \mathrm{c}_{t}^{D}-(\omega-1) \mathrm{Z}_{t}^{D}\right] .
$$

If $\frac{1}{\rho}>-(\omega-1)$ (which is always satisfied if $\omega \geq 1$ ), relative employment is related negatively to the consumption differential. If $\omega=1, \mathrm{~L}_{t}^{D}=-\mathrm{c}_{t}^{D}$. In this case, equations (47) and (50) imply $\mathrm{c}_{t}^{D}=\mathrm{w}_{t}^{D}$. Substituting this result into equation (49) yields $\mathrm{L}_{t}^{D}=0$. Thus, it must be the case that, if the elasticity of substitution between domestic and foreign goods is one, $c_{t}=c_{t}^{*}, w_{t}=w_{t}^{*}$, and $\mathrm{L}_{t}=\mathrm{L}_{t}^{*}$. Consistent with Cole and Obstfeld's (1991) original result, unitary intratemporal elasticity of substitution ensures that domestic and foreign consumption, the real wage, and employment are equal regardless of productivity, mimicking features of the economy under internationally complete asset markets.

Now, log-linearizing the consumption function (40) and its foreign counterpart, taking the difference of the resulting equations, and recalling asset market equilibrium yields:

$$
\mathrm{c}_{t}^{D}=\frac{\rho(1-\beta)}{\beta(1-a)} \mathrm{B}_{t}+\mathrm{h}_{t}^{D} .
$$

The consumption differential in each period reflects the net foreign asset position of the two economies and the differential between domestic and foreign human wealth.

Relative human wealth obeys:

$$
\mathrm{h}_{t}^{D}=\beta \mathrm{h}_{t+1}^{D}+(1-\beta) \mathrm{w}_{t}^{D}
$$

Today's difference in the real value of an agent's lifetime is higher the higher tomorrow's difference and today's real wage differential. Because $\mathrm{w}_{t}=\mathrm{w}_{t}^{*}$ when $\omega=1$, unitary intratemporal elasticity of substitution implies $\mathrm{h}_{t}=\mathrm{h}_{t}^{*}$.

Using (49), (50), and (51), relative human wealth can be written as a function of the stock of net foreign assets and the productivity differential:

$$
\mathrm{h}_{t}^{D}=\frac{\beta[1+\rho(\omega-1)]}{\rho \omega+\beta(1-\rho)} \mathrm{h}_{t+1}^{D}+\frac{\rho(1-\rho)(1-\beta)^{2}}{\beta(1-a)[\rho \omega+\beta(1-\rho)]} \mathrm{B}_{t}+\frac{\rho(1-\beta)(\omega-1)}{\rho \omega+\beta(1-\rho)} \mathrm{Z}_{t}^{D} .
$$


To complete the solution, we need an equation for asset accumulation. Log-linearizing the laws of motion for domestic and foreign net foreign assets yields:

$$
\mathrm{B}_{t+1}=\frac{1}{1+n}\left(\frac{1}{\beta} \mathrm{B}_{t}+\mathrm{y}_{t}-\mathrm{c}_{t}\right), \quad \mathrm{B}_{t+1}^{*}=\frac{1}{1+n}\left(\frac{1}{\beta} \mathrm{B}_{t}^{*}+\mathrm{y}_{t}^{*}-\mathrm{c}_{t}^{*}\right) .
$$

$\mathrm{B}$ and $\mathrm{B}^{*}$ are defined as $\frac{d B}{\bar{c}}$ and $\frac{d B^{*}}{\bar{c}^{*}}$, respectively, because $\bar{B}=\bar{B}^{*}=0$. As steady-state asset holdings are zero, changes in the real interest rate have no direct impact on asset accumulation. If $\omega=1, \mathrm{y}_{t}=\mathrm{y}_{t}^{*}$ and $\mathrm{c}_{t}=\mathrm{c}_{t}^{*}$. Hence, to preserve asset market equilibrium $\left(\mathrm{B}_{t}^{*}=-\frac{a}{1-a} \mathrm{~B}_{t}\right)$, it must be $\mathrm{B}_{t}=\mathrm{B}_{t}^{*}=0 \forall t$ : If the elasticity of substitution between domestic and foreign goods is one, consumption levels are equalized across countries, accumulation of net foreign assets plays no role in the transmission of shocks, and current accounts are always zero: $\mathrm{y}_{t}=\mathrm{c}_{t}$ and $\mathrm{y}_{t}^{*}=\mathrm{c}_{t}^{*}$. Corsetti and Pesenti (2001a) extended Cole and Obstfeld's (1991) result to the case of sticky prices. The resulting tractability of the model made the $\omega=1$-assumption a benchmark for much of the subsequent literature.

Using equations (48), (49), (50), (51), and asset market equilibrium, the difference between the laws of motion in (54) yields:

$$
\mathrm{B}_{t+1}=\frac{1+\rho(\omega \beta-1)}{\beta(1+n)[1+\rho(\omega-1)]} \mathrm{B}_{t}-\frac{\omega(1-a)}{(1+n)[1+\rho(\omega-1)]} \mathbf{h}_{t}^{D}+\frac{(\omega-1)(1-a)}{(1+n)[1+\rho(\omega-1)]} \mathrm{Z}_{t}^{D},
$$

Equations (53) and (55) constitute a system of two equations in two unknowns (the endogenous state variable $B$ and the forward-looking variable $\mathrm{h}^{D}$ ) plus the exogenous relative productivity term $\mathrm{Z}^{D}$. For the purpose of verifying determinacy of the solution, focus temporarily on endogenous variables. We can write:

$$
\left[\begin{array}{c}
\mathrm{h}_{t+1}^{D} \\
\mathrm{~B}_{t+1}
\end{array}\right]=M\left[\begin{array}{c}
\mathrm{h}_{t}^{D} \\
\mathrm{~B}_{t}
\end{array}\right], M \equiv\left[\begin{array}{cc}
\frac{\rho \omega+\beta(1-\rho)}{\beta[1+\rho(\omega-1)]} & -\frac{\rho(1-\rho)(1-\beta)^{2}}{\beta^{2}(1-a)[1+\rho(\omega-1)]} \\
-\frac{\omega(1-a)}{(1+n)[1+\rho(\omega-1)]} & \frac{1+\rho(\omega-1)}{\beta(1+n)[1+\rho(\omega-1)]}
\end{array}\right] .
$$

If $n=0$, the matrix $M$ has eigenvalues $\frac{1}{\beta}$ and 1 . Since $\beta<1$, the number of eigenvalues outside the unit circle equals the number of non-predetermined variables, ensuring that the system of equations (53) and (55) has a determinate solution (Blanchard and Kahn, 1980). The second eigenvalue exactly equal to 1 is consistent with non-stationary net foreign asset dynamics in the case $n=0$. If $n$ becomes strictly positive, this eigenvalue is pulled inside the unit circle, delivering stationarity of net foreign assets. Graphing the characteristic polynomial for the matrix $M$ shows that the solution remains determinate when $n>0$.

I assume $\mathrm{Z}_{t}=\phi \mathrm{Z}_{t-1}, \mathrm{Z}_{t}^{*}=\phi \mathrm{Z}_{t-1}^{*}, \forall t>0,0 \leq \phi \leq 1$ ( $t=0$ is the time of an initial, surprise impulse below). Hence, $Z_{t}^{D}=\phi Z_{t-1}^{D}$. If $\phi=1$, impulses to productivity have permanent consequences, causing the economy to move to a new steady state, different from that described in Section 3.2 , because of non-stationarity of the productivity process. 
The stock of net foreign assets and the levels of exogenous productivities describe the state of the economy in each period. The solution of the system (53)-(55) can be written as:

$$
\begin{aligned}
& \mathrm{B}_{t+1}=\eta_{B B} \mathrm{~B}_{t}+\eta_{B Z^{D}} \mathrm{Z}_{t}^{D}, \\
& \mathrm{~h}_{t}^{D}=\eta_{h^{D} B} \mathrm{~B}_{t}+\eta_{h^{D} Z^{D}} \mathrm{Z}_{t}^{D},
\end{aligned}
$$

where $\eta_{B B}$ is the elasticity of time- $t+1$ assets to their time- $t$ level, $\eta_{B Z^{D}}$ is the elasticity of time- $t+1$ assets to the time- $t$ productivity differential between home and foreign, $\eta_{h^{D} B}$ is the elasticity of $\mathrm{h}_{t}^{D}$ to time- $t$ assets, and $\eta_{h^{D} Z^{D}}$ is the elasticity of $\mathrm{h}_{t}^{D}$ to $\mathrm{Z}_{t}^{D}$. The values of the elasticities $\eta$ as functions of the structural parameters of the model can be obtained with the method of undetermined coefficients as in Campbell (1994). ${ }^{40}$ Stationarity of net foreign assets requires $\eta_{B B}<1$. As mentioned above, this happens whenever $n>0$. A favorable shock to relative domestic productivity causes domestic agents to accumulate net foreign assets to smooth consumption dynamics for plausible parameter values if $\phi<1$ (see below). Hence, $\eta_{B Z^{D}}>0$. Plausible parameter values ensure that $\eta_{h^{D} B}$ and $\eta_{h^{D} Z^{D}}$ are positive too. ${ }^{41}$

If $\omega=1, \eta_{h^{D} Z^{D}}=\eta_{B Z^{D}}=0$ : Asset accumulation does not react to shocks $\left(\mathrm{B}_{t}=0\right)$ and $\mathrm{h}_{t}^{D}=0 \forall t$. In this case, one-time productivity shocks have only temporary effects.

Given any pair of endogenous, non-state variables $x$ and $x^{*}$, the solution for their difference can be written in a similar fashion to $(57)$,

$$
\mathrm{x}_{t}^{D}=\eta_{x^{D} B} \mathrm{~B}_{t}+\eta_{x^{D} Z^{D}} \mathrm{Z}_{t}^{D}
$$

and the relevant elasticities can be obtained with the method of undetermined coefficients. ${ }^{42}$

\subsubsection{Impulse Responses}

Equations (56)-(58) can be used to trace the response of cross-country differences to impulses to productivity and illustrate the importance of some key parameters.

I start with the following benchmark parameter values: $\beta=.99, \rho=.33, \omega=1.2, a=.5$, and $n=.01$. Periods are interpreted as quarters. The choice of $n$ is higher than realistic, at least if one has developed economies in mind and $n$ is interpreted strictly as the rate of growth of population. ${ }^{43}$ I use $n=.01$ as a benchmark example and discuss the implications of lower (and higher) values in

\footnotetext{
${ }^{40}$ See Appendix B.

${ }^{41}$ Cavallo and Ghironi (2002) show that a sticky-price variant of the model can replicate the observed qualitative pattern of foreign debt accumulation and exchange rate appreciation for the U.S. if $\phi=1$. More plausibly, inclusion of physical capital in the model will make it possible to reproduce U.S. dynamics for non-permanent shocks.

${ }^{42}$ Details are in Appendix B.

${ }^{43}$ The average rate of quarterly population growth for the U.S. between 1973:1 and 2000:3 has been .0025 .
} 
what follows. ${ }^{44}$ In contrast to $n$, I use a lower than realistic value of $\omega$, consistent with the RBC literature. Estimates from the trade literature suggest that values significantly above 1 would be reasonable. ${ }^{45}$ I explore the consequences of higher $\omega$ below.

Figure 1 shows the dynamics of aggregate per capita real net foreign assets, the employment (or labor effort) differential, the GDP differential, and the consumption differential following a 1 percent increase in relative domestic productivity. ${ }^{46}$ I consider three values of $\phi$ in the figure $(0$, .5 , and .9) and omit (but mention) the responses for $\phi=1$. Table 2 summarizes the values of the elasticities $\eta$ implied by the benchmark parameterization as $\phi$ varies.

When $\phi<1$, the home economy accumulates net foreign assets following the shock to smooth the effect of the latter on consumption (Figure 1.a). When the shock is purely temporary $(\phi=0)$, net foreign assets decrease monotonically in the periods after the initial one. A more persistent increase in productivity $(0<\phi<1)$ causes the home economy to continue accumulating assets for several quarters before settling on the downward path to the steady state. In all cases, the speed at which net foreign assets return to the steady state once the productivity differential has died out is extremely slow, consistent with the low rate of entry of new households in the economy. This is consistent with the inability of statistical tests such as augmented Dickey-Fuller to detect stationarity over samples that are far too short if the speed of return to the steady state is indeed as slow as in Figure 1.a (or even slower).

Appendix B shows that the sign of $\eta_{L^{D} B}$ and $\eta_{y^{D} B}$ (the elasticities of the employment and real GDP differentials to net assets) is the opposite of the sign of $\eta_{c^{D}}{ }_{B}$ (the elasticity of the consumption differential to net assets). For most plausible combinations of values of the structural parameters $\beta, \rho, \omega, \phi, a$, and $n$, it is $\eta_{c^{D} B}>0$. Intuitively, accumulation of net foreign assets allows the home economy to sustain a higher consumption path than foreign. It follows that $\eta_{L^{D} B}<0$ and $\eta_{y^{D} B}<0$ : Ceteris paribus, accumulation of net foreign assets causes domestic agents to supply less labor than foreign, the domestic real wage and relative price are higher than abroad (the terms of trade appreciate), and domestic GDP falls relative to foreign. On impact, a favorable shock to domestic productivity causes domestic employment and GDP to rise above foreign in figures $1 . b$ and 1.c (because $\eta_{L^{D} Z^{D}}$ and $\eta_{y^{D} Z^{D}}$, the elasticities of the employment and GDP differentials to relative productivity, are positive). ${ }^{47}$ Domestic employment and GDP are higher than foreign

\footnotetext{
${ }^{44}$ Extending the model to incorporate probability of death as in Blanchard (1985) would make it possible to reproduce the dynamics generated by $n=.01$ in this paper with a lower rate of entry of new households by choosing the proper value of the probability of death. The choice of .01 can thus be rationalized in terms of mimicking the behavior of a more complicated, yet largely isomorphic setup.

${ }^{45}$ See Feenstra (1994), Harrigan (1993), Hummels (1999), Shiells, Stern, and Deardorff (1986), and Trefler and Lai (1999).

${ }^{46}$ The responses in this figure and in the following ones have been rescaled by multiplying by 100 , so that, for instance, .3 denotes .3 percent rather than 30 percent. Impulse responses for other variables are available on request.

${ }^{47}$ The positive elasticity of equilibrium employment to productivity is related to the negative elasticity of the
} 
for a longer time the more persistent the shock. ${ }^{48}$ But the latter causes net assets entering the following period to be positive $\left(\eta_{B Z^{D}}>0\right)$ if $\phi<1$. Hence, $\eta_{y^{D}{ }_{B}} \eta_{B Z^{D}}<0$ and $\phi<1$ ensure that the real GDP differential is returning to the steady state from the period after the shock on. (In particular, $\eta_{L^{D} B}<0$ and $\eta_{y^{D} B}<0$ cause the employment and GDP differentials to return to zero from (slightly) below after $Z^{D}$ has died out.) Instead, the consumption differential is positive throughout the transition dynamics (and larger the more persistent the shock, Figure 1.d). Note that, because $\eta_{L^{D} B}$ and $\eta_{y^{D} B}$ are very small, the deviations of the employment and GDP differentials from the steady state become very small once the productivity shock has died out. Cross-country differences caused by net foreign asset accumulation are quantitatively small when $\omega$ is close to 1 . Consistent with intertemporal optimization, the consumption differential is smoother than the GDP differential. The deviation of the consumption differential from the steady state is substantially smaller than that of the employment and GDP differentials even in the first few periods after the shock.

The home economy accumulates no assets if the shock is permanent $(\phi=1)$. In this case, domestic GDP and consumption rise permanently above foreign exactly by the same amount in the period of the shock. Instead, there is no employment differential.

To further illustrate the role of $n$, figures 2 and 3 show the responses of net assets and GDP and consumption differentials to a one-time productivity impulse with no persistence $(\phi=0)$ in the cases $n=0$ and $n=.5$, respectively. The $n=0$-case corresponds to a non-stationary, flexible-price version of the standard Obstfeld-Rogoff $(1995 a, 1996$ Ch. 10) model. The temporary shock has permanent consequences on assets and the consumption and GDP differentials. As the $n=.5$-case shows, raising $n$ to an absurd value makes the speed of convergence of asset holdings to the steady state much faster (in this case, $\eta_{B B}=.67$ as opposed to $\eta_{B B}=.994$ with $n=.01$ ). ${ }^{49}$

Finally, Figure 4 displays the responses of assets and GDP and consumption differentials to a zero-persistence shock when $n=.01$ but $\omega=4$. The range of variation of endogenous variables caused by the shock in this case is an order of magnitude larger than with $\omega=1.2$. Cross-country differences caused by asymmetric shocks are bigger if goods are more highly substitutable across countries.

relative price differential (see Appendix B). Domestic equilibrium employment rises above foreign because a lower domestic real price generates more demand for home goods.

${ }^{48}$ Though $\eta_{L^{D} Z^{D}}=0$ if $\phi=1$.

${ }^{49}$ Lane (2002) argues that the setup of this paper cannot generate fast convergence to the steady state. The (extreme) example of this paragraph shows that this claim is incorrect. The true question is whether or not one wants to have fast convergence of net foreign assets to the steady state. The evidence on time series properties of net foreign assets in the Introduction suggests that slow convergence to the steady state is empirically appealing. 


\subsection{World Averages}

Completing the solution of the model requires solving for the levels of world aggregate variables, to be used in conjunction with cross-country differences to determine individual country variables.

World averages are defined as weighted averages of individual country variables, with weights $a$ for home and $1-a$ for foreign, respectively. The following equations hold:

$$
\begin{gathered}
\mathrm{RP}_{t}^{W}=\mathrm{w}_{t}^{W}-\mathrm{Z}_{t}^{W} \\
\mathrm{~L}_{t}^{W}=-\omega \mathrm{RP}_{t}^{W}+\mathrm{y}_{t}^{W}-\mathrm{Z}_{t}^{W} \\
\mathrm{y}_{t}^{W}=\mathrm{RP}_{t}^{W}+\mathrm{L}_{t}^{W}+\mathrm{Z}_{t}^{W} \\
\mathrm{y}_{t}^{W}=\mathrm{c}_{t}^{W} \\
\mathrm{w}_{t}^{W}=\mathrm{c}_{t}^{W}+\frac{\rho}{1-\rho} \mathrm{L}_{t}^{W}
\end{gathered}
$$

Equation (59) is the optimality condition that relates world prices to marginal costs. Equation (60) determines world labor demand, which is a function of world demand of the consumption basket. Equation (61) yields the level of world production. Equation (62) is the world market clearing condition, equivalent to international asset market equilibrium. Equation (63) is the worldwide labor-leisure tradeoff. Equations (59)-(63) constitute a system of five equations in five unknowns$\mathrm{RP}_{t}^{W}, \mathrm{w}_{t}^{W}, \mathrm{~L}_{t}^{W}, \mathrm{y}_{t}^{W}$, and $\mathrm{c}_{t}^{W}$-as functions of exogenous world productivity, $\mathrm{Z}_{t}^{W}$. The solution is (regardless of the value of $\omega$ ):

$$
\begin{aligned}
\mathrm{RP}_{t}^{W} & =\mathrm{L}_{t}^{W}=0 \\
\mathrm{w}_{t}^{W} & =\mathrm{y}_{t}^{W}=\mathrm{c}_{t}^{W}=\mathrm{Z}_{t}^{W}
\end{aligned}
$$

World productivity changes translate into changes in GDP, consumption, and the real wage. These changes have offsetting effects on real pricing and employment, which remain insulated from changes in productivity. Equation (43) yields $\mathrm{h}_{t}^{W}=\mathrm{w}_{t}^{W}=\mathrm{Z}_{t}^{W}$. Finally, equation (45) implies that the world real interest rate between today and tomorrow must equal world productivity growth between the two periods:

$$
r_{t+1}=z_{t+1}^{W}-z_{t}^{W}
$$

From these results, it follows that a purely temporary productivity shock $(\phi=0)$ has only transitory effects on world aggregates and the real interest rate. In particular, $r_{t_{0}+1}=-Z_{t_{0}}^{W}$, and $r_{t}=0 \forall t>t_{0}+1$. 


\subsection{Complete Asset Markets}

Suppose now that the elasticity of substitution between domestic and foreign goods differs from 1, but agents at home and abroad have access to complete asset markets in one-period, contingent securities. (I do not present the complete markets economy in detail. Rather, I focus on the key implications of the complete markets assumption. The underlying setup is the extension of the model in the technical appendix of Benigno and Benigno, 2001, to the case in which $\omega \neq 1$.) In this case, net foreign holdings of contingent securities (net foreign assets) play no role in the solution for the dynamics of other endogenous variables. To see this, observe first that the solution for world aggregates is left unaffected by the change in the menu of assets available to agents. The results in (64) still describe aggregate world dynamics following changes in productivity. The solution for cross-country differences is instead affected as follows.

Starting from a symmetric steady state, perfect "risk" sharing in complete asset markets implies that the consumption differential is zero in all periods: $c_{t}^{D}=0 \forall t .{ }^{50}$ Substituting this into the relative labor-leisure tradeoff condition shows that the cross-country employment differential is proportional to the real wage differential under complete markets:

$$
\mathrm{w}_{t}^{D}=\frac{\rho}{1-\rho} \mathrm{L}_{t}^{D}
$$

Equation (50) and $c_{t}^{D}=0$ yield the solution for the employment differential as a function of relative productivity. This can be combined with (65) to solve for the equilibrium real wage differential. It is:

$$
\begin{aligned}
\mathrm{L}_{t}^{D} & =\frac{(1-\rho)(\omega-1)}{1+\rho(\omega-1)} \mathrm{Z}_{t}^{D}, \\
\mathrm{w}_{t}^{D} & =\frac{\rho(\omega-1)}{1+\rho(\omega-1)} \mathrm{Z}_{t}^{D} .
\end{aligned}
$$

Hence, the relative pricing and GDP equations (46) and (48) return:

$$
\begin{aligned}
\mathrm{RP}_{t}^{D} & =-\frac{1}{1+\rho(\omega-1)} \mathrm{Z}_{t}^{D} \\
\mathrm{y}_{t}^{D} & =\frac{\omega-1}{1+\rho(\omega-1)} \mathrm{Z}_{t}^{D} .
\end{aligned}
$$

At no point in the solution did we have to use the law of motion for net foreign asset holdings. When asset markets are complete and $\omega \neq 1$, net foreign holdings of contingent securities do move over time in response to relative GDP movements. However, these changes in net foreign assets are determined residually. They do not affect the dynamics of other endogenous variables,

\footnotetext{
${ }^{50}$ See the technical appendix of Benigno and Benigno (2001) and Ljungqvist and Sargent (2000) on the properties of complete markets.
} 
which are independent of the history of the economy as represented by the stock of net foreign assets accumulated by each country. For this reason, it is irrelevant for the results of this paper whether markets are complete only at the international level, preserving the market incompleteness represented by intergenerational heterogeneity in the benchmark economy of this paper, or whether markets are complete across and within countries, so that intergenerational differences inside each country are "insured away." 51

\subsection{Country Dynamics and Asset Accumulation}

Given solutions for differences and world averages, individual country levels of variables can be obtained easily. For any pair of variables $\mathrm{x}$ and $\mathrm{x}^{*}$, it is $\mathrm{x}=\mathrm{x}^{W}+(1-a) \mathrm{x}^{D}$ and $\mathrm{x}^{*}=\mathrm{x}^{W}-a \mathrm{x}^{D}$.

I perform a simple experiment to gauge the role of net foreign asset accumulation for individual country dynamics. Suppose reality is such that markets are incomplete, $\omega=\omega^{R} \neq 1$, and convergence of net foreign assets to the steady state after non-permanent, asymmetric productivity shocks is slow. I am interested in evaluating what is missed by trying to approximate reality with any of the following alternatives: (a) Assuming that markets are incomplete, $\omega=\omega^{R}$, and net foreign assets return to the steady state quickly after non-permanent shocks (an unrealistically high value of $n)$; (b) Assuming incomplete markets in a non-stationary, representative agent setup in which $\omega=\omega^{R}$ and net foreign assets never return to the steady state $(n=0)$; $(c)$ Assuming that markets are incomplete, but $\omega=1$ as in Corsetti and Pesenti $(2001 a) ;(d)$ Assuming $\omega=\omega^{R}$ with complete asset markets. ${ }^{52}$

The results of the previous sub-sections already allow us to draw a number of qualitative conclusions. The Corsetti-Pesenti assumption that $\omega=1$ implies that consumption and employment levels in the two countries are equalized regardless of productivity and that consumption is tied to GDP, so that net foreign assets do not move after shocks. In this case, there is no endogenous persistence in the changes in consumption and other variables triggered by changes in productivity. If the true elasticity of substitution between domestic and foreign goods differs from 1, the paths of variables following shocks are different. Countries run current account imbalances following asymmetric shocks. They accumulate (or decumulate) foreign assets. If asset markets are incomplete, cross-country differences in aggregate per capita levels of consumption and other variables persist (beyond the persistence of the shock if this is not permanent) until net foreign assets return to the steady state. If asset markets are complete and $\omega \neq 1$, the cross-country consumption differential is

\footnotetext{
${ }^{51}$ If $\omega=1$, the complete and incomplete markets solutions coincide.

${ }^{52}$ Tille (2001) analyzes the consequences of differences in the values of $\theta$ (the elasticity of substitution between individual goods produced inside each country) and $\omega$ for the transmission and welfare effects of exogenous monetary shocks in a non-stationary, incomplete markets model with nominal rigidity. I focus on how important it is if $\omega$ differs from 1 for model dynamics under incomplete and complete markets.
} 
zero in all periods, and there is no endogenous persistence in employment, GDP, wage, and relative price differentials.

Section 4.2 showed that $\mathrm{y}_{t}^{W}=\mathrm{c}_{t}^{W}=\mathrm{Z}_{t}^{W}$ and $\mathrm{L}_{t}^{W}=0$ regardless of $\omega$ and of the structure of asset markets. If $\omega=1, \mathrm{y}_{t}=\mathrm{y}_{t}^{*}=\mathrm{c}_{t}=\mathrm{c}_{t}^{*}=\mathrm{w}_{t}=\mathrm{w}_{t}^{*}=\mathrm{Z}_{t}^{W}$ and $\mathrm{L}_{t}^{D}=0$. But $\mathrm{L}_{t}^{W}=\mathrm{L}_{t}^{D}=0$ implies $\mathrm{L}_{t}=\mathrm{L}_{t}^{*}=0$. In contrast to the $\omega \neq 1$-case, employment levels in individual countries do not react to productivity under the assumption of unitary intratemporal elasticity of substitution between domestic and foreign goods. If the true elasticity of substitution between domestic and foreign goods differs from 1 , the description of the economy provided by the $\omega=1$-approximation generates errors in the characterization of the impact effects of a productivity change and misses the transition dynamics caused by asset accumulation. If asset markets are incomplete in reality, assuming complete markets erroneously removes the dependence of the equilibrium on the history of asset accumulation.

The open question is how significant the differences in results across specifications are from a quantitative perspective. For instance, the impulse responses for the benchmark parameterization of Section 4.1.1 suggest that errors caused by the $\omega=1$-approximation (alternative $(c)$ above) may be more significant in the characterization of the path of employment than in that of consumption, the reason being the absence of a reaction of employment to productivity in the $\omega=1$-case. Consumption differentials generated by asset accumulation per se are likely to be small because of the small elasticity of the consumption differential to net foreign assets for plausible parameter values. Nevertheless, we expect the error in the characterizations of consumption generated by alternatives $(c)$ and $(d)$ to become larger if the true $\omega$ is further away from 1 and if productivity shocks are more persistent (if $\phi$ is higher).

Figure 5 presents the responses of home consumption, the terms of trade, employment, and GDP to a 1 percent impulse to home productivity for the benchmark economy and alternatives $(a)-(d)$. (I include the responses of the terms of trade to facilitate comparison with the results of Baxter and Crucini, 1995, and Schmitt-Grohé and Uribe, 2003. I focus on impulse responses for the home economy. Results for the foreign economy are similar. Diagrams are available upon request.) I assume the same parameter values as in Section 4.1.1 for the benchmark economy, which I repeat here for convenience: $\beta=.99, \rho=.33, \omega=\omega^{R}=1.2, a=.5$, and $n=.01$. I assume that the shock has relatively high persistence: $\phi=.9$ (although this value is at the low end of the range that can be found in the RBC literature). I set $n=.5$ in alternative ( $a$ ) (stationary model, fast convergence). ${ }^{53}$ Figure 6 repeats the exercise for $\omega^{R}=4$. The diagrams on the left side of each figure are the impulse responses (rescaled by multiplying times 100), the diagrams on the right present the differences between the response of the variable under consideration and the responses

\footnotetext{
${ }^{53}$ The value of $n$ is irrelevant in the $\omega=1$ and complete markets cases.
} 
under alternatives $(a)-(d)$.

The home economy consumes and produces the same good as the rest of the world in Baxter and Crucini (1995) and Schmitt-Grohé and Uribe (2003). This amounts to $\omega \rightarrow \infty$ in the setup of this paper: Goods produced at home and abroad are perfect substitutes. When this happens, the relative price ratio between home and foreign (the terms of trade) is 1 in all period (or 0 in log-linear terms). To clarify the comparison of my results with those of Baxter and Crucini (1995) and Schmitt-Grohé and Uribe (2003), Figure 7 repeats the exercise of figures 5 and 6 for $\omega^{R}=1,000,000$.

The $\omega=1$ and complete markets approximations (alternatives $(c)$ and $(d)$, respectively) generate identical paths of consumption (figures 5.a.a, 6.a.a, and 7.a.a) that are smoother than those for the other cases. Similarly, Schmitt-Grohé and Uribe (2003) find that complete markets generate a smoother response of consumption to productivity shocks than alternative model specifications. Figure 5.a.a suggests that differences across specifications for consumption dynamics are negligible, at least for approximately three years after the shock, when $\omega^{R}=1.2$. The widest difference in consumption responses to the shock at time 0 , when the shock happens, is that between the incomplete markets, non-stationary case (alternative $(b)$ ) and the $\omega=1$-consumption path, which amounts to .0076 percent of steady-state consumption. ${ }^{54}$ This difference remains constant over time. Figure 5. a.b plots the differences in responses between the benchmark economy and the alternatives as percentage of steady-state consumption. The difference between the benchmark and alternative (a) (fast convergence) starts at .0018 percent, increases initially, peaks at .0041 percent, and then decreases toward 0 as consumption returns to the steady state in both cases. The absolute value of the difference between the benchmark and alternative $(b)$ starts at .0028 percent and increases monotonically as consumption in the benchmark converges to the steady state, whereas it settles at a permanently higher level when $n=0$. The difference between the benchmark economy and alternatives $(c)$ and $(d)$, which decreases over time owing to stationarity of consumption in all three cases, is initially .0048 percent. This paper does not address the question of whether these differences are negligible on welfare grounds. (This should be done in an explicitly stochastic setting.) But it is certainly the case that differences appear negligible from a positive perspective if $\omega^{R}$ is close to 1 .

As expected, differences across specifications widen significantly when $\omega^{R}=4$ (Figure 6.a.b). As for the case $\omega^{R}=1.2$, the widest difference is that between alternative $(b)$ and alternatives $(c)$

\footnotetext{
${ }^{54}$ Let $\widetilde{\mathrm{c}}_{t}^{i}$ denote the rescaled deviation of consumption from the steady state during period $t$ in scenario $i$ in Figure 5.a.a. Then, consumption after a 1 percent productivity shock in scenario $i$ is $c_{t}^{i}=\bar{c}+\frac{\widetilde{\mathrm{c}}_{t}^{i}}{100} \bar{c}$, and $\widetilde{\mathrm{c}}_{t}^{i}-\widetilde{\mathrm{c}}_{t}^{j}=$

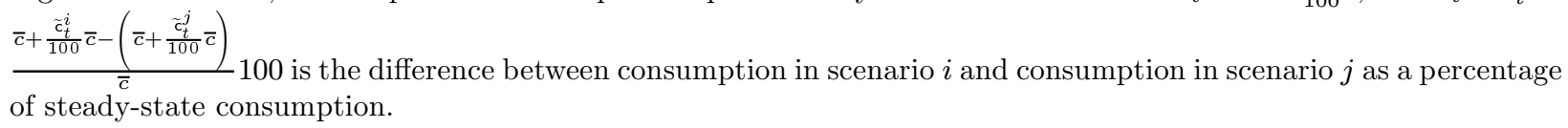


and $(d)$, which is .0344 percent of steady-state consumption. The difference between the benchmark and alternative $(a)$ starts at .0048 percent, peaks at .0228 percent, and falls to zero over time. The absolute value of the difference between the benchmark and alternative $(b)$ starts at .0059 percent and increases over time (.01 percent after 28 quarters). Finally, the difference relative to alternatives $(c)$ and $(d)$ starts at .0285 percent and decreases over time. A higher, but arguably realistic value of the elasticity of substitution between domestic and foreign goods in consumption as suggested by the trade literature results in differences across consumption paths for different model specifications in the short and medium run that remain small, but harder to classify as negligible.

What happens if $\omega \rightarrow \infty$, so that both countries produce the same good and there is no scope for terms of trade dynamics in the model? The difference between the benchmark and alternatives $(c)$ and $(d)$ rises to .0458 percent (Figure 7.a.b). Increasing the substitutability across domestic and foreign goods from close to 1 to a value in the range estimated by the trade literature causes the difference to increase significantly. The effect of going all the way to perfect substitutability is smaller. Consistent with Baxter and Crucini's (1995) and Schmitt-Grohé and Uribe's (2003) findings, the difference between consumption paths under the benchmark and under complete markets is noticeable, but small. ${ }^{55}$ Interestingly, Figure 7.a.b shows that the differences between the benchmark economy and the non-stationary alternative is extremely small for the first 8 quarters or so of the exercise, significantly smaller than for the previous values of $\omega^{R}\left(-4.2 \cdot 10^{-8}\right.$ on impact against -.0028 when $\omega^{R}=1.2$ and -.0059 when $\omega^{R}=4$ ). (Also the difference between the benchmark and alternative (a) starts extremely small in this case.) Schmitt-Grohé and Uribe's (2003) result that the difference in short-run dynamics between a stationary model with plausible speed of convergence of net foreign assets to the steady state and a non-stationary economy is negligible in the short run emerges also from the model of this paper when home and foreign goods are perfect substitutes. This suggests that the absence of terms of trade dynamics implied by perfect substitutability across domestic and foreign goods is important to explain Schmitt-Grohé and Uribe's findings. Once domestic and foreign products are allowed to differ and the terms of trade respond to shocks, differences between incomplete markets specifications become more pronounced also in the short run. Put differently, terms of trade movements are important to generate noticeable short-run differences in responses across plausible incomplete markets scenarios. ${ }^{56}$

Results on employment (figures 5.b.a, 6.b.a, and 7.b.a) are similar. Differences in responses

\footnotetext{
${ }^{55}$ See also Heathcote and Perri (2002) and Kehoe and Perri (2002).

${ }^{56}$ As shown in the figures, the home economy's terms of trade $\left(\mathrm{RP}^{D}\right)$ deteriorate as a consequence of a favorable productivity shock that increases the supply of domestic goods when $\omega$ is finite. In the case of a non-permanent shock, a lowering of the domestic relative price below foreign is responsible for higher labor effort at home than abroad. It should be noted that differences across scenarios cannot follow from differences in the dynamics of the world real interest rate, as this is a function of the path of world productivity only, which does not change across scenarios.
} 
are small. They are negligible if $\omega^{R}=1.2$, except relative to the $\omega=1$-approximation. They become wider if $\omega^{R}=4$. Figure 5.b.b shows that the difference between the benchmark and the non-stationary case starts at .0021 percent of steady-state labor effort when $\omega^{R}=1.2(.0079$ percent when $\omega^{R}=4$, Figure 6.b.b) and increases over time. The absolute value of the difference between the benchmark and the complete markets economy (alternative $(d)$ ) starts at .0036 when $\omega^{R}=1.2\left(.0384\right.$ percent when $\left.\omega^{R}=4\right)$ and decreases over time. The $\omega=1$-approximation (alternative $(c)$ ) causes an initial error equal to .0592 percent when $\omega^{R}=1.2$, which increases to .4666 percent when $\omega^{R}=4$. (The labor effort and GDP differences between the benchmark and the $\omega=1$-approximation are measured on the secondary vertical axis.) As suggested above, the Corsetti-Pesenti (2001a) assumption of unitary elasticity of substitution between domestic and foreign goods can cause more significant errors in the description of labor effort dynamics by implying that employment does not react to productivity shocks. If the true $\omega$ is significantly different from 1 (but finite), the difference between the benchmark and the complete markets model $(d)$ in terms of employment dynamics is somewhat larger than the difference in consumption responses. As figures $7 a . b$ and 7.c. $b$ show, the same result emerges when domestic and foreign goods are perfect substitutes, in contrast to Schmitt-Grohé and Uribe's (2003) conclusion that only differences in consumption dynamics are noticeable in this case. The wealth effect of net foreign asset accumulation on the supply of labor effort at home and abroad in a two-country, rather than small open economy, setup motivates this difference in results. However, Schmitt-Grohé and Uribe's result that there is a negligible difference between the (plausible) stationary case and the non-stationary one in the short run emerges also with respect to labor effort when both goods produced at home and abroad are perfect substitutes.

Approximation errors caused by alternatives $(a),(b)$, and $(d)$ are negligible when one considers GDP in the case $\omega^{R}=1.2$ (Figure 5.d.b). (In period 0, the differences $(a)$ - benchmark, benchmark $-(b)$, and $(d)$ - benchmark are close to .0002 , .0003, and .0006 percent of steady-state GDP respectively.) As for employment, the $\omega=1$-approximation causes the largest error: .0932 percent of steady state GDP at $t=0$. Higher substitutability across goods amplifies the errors (Figure 6.d.b): In period 0, the differences $(a)$ - benchmark, benchmark - $(b)$, benchmark $-(c)$, and $(d)-$ benchmark are $.0049, .0059, .72$, and .0288 percent, respectively. If the true value of $\omega$ is significantly different from 1, the Corsetti-Pesenti model results in the largest error in the characterization of GDP dynamics following productivity shocks. The inaccuracy of the complete markets model is of the same size as for consumption dynamics. Again in contrast to Schmitt-Grohé and Uribe's (2003) findings, perfect substitutability between domestic and foreign goods and the resulting absence of terms of trade movements cause a wider difference between GDP responses relative to consumption responses under the benchmark and alternative $(d)$. However, $\omega \rightarrow \infty$ reproduces Schmitt-Grohé 
and Uribe's finding of negligible differences in GDP dynamics across the benchmark specification and the non-stationary alternative.

\subsubsection{Permanent Shocks}

Baxter and Crucini (1995) find that the difference in impulse responses between complete and incomplete markets economies is amplified if shocks are permanent $(\phi=1)$. For comparison of results, Figure 8 presents the responses of home consumption, the terms of trade, labor effort, and GDP to a permanent domestic productivity shock with $\omega^{R}=1.2,4$, and 1,000,000. Since endogenous, non-predetermined variables jump immediately to the new permanent position when $\phi=1$, the panels in Figure 8 have $\omega^{R}$ on the horizontal axis and the response level on the vertical axis.

Net foreign assets do not move in the model of this paper if asymmetric shocks are permanent. When $\phi=1$, optimal consumption smoothing dictates that consumption and GDP increase exactly by the same amount on impact and remain there forever. This is true regardless of the value of the rate of entry of new households in the economy $(n)$. More specifically, since agents do not accumulate assets in response to permanent shocks, the responses of consumption, labor effort, and GDP are identical regardless of the value of $n$, including the non-stationary case $n=0$.

As in the case of a non-permanent shock, complete markets and the Corsetti-Pesenti (2001a) setup yield the same response of consumption to a permanent shock regardless of the value of $\omega^{R}$. The response reflects the impact of the shock on world productivity, i.e., .5 percent in all cases. The response under complete markets and the Corsetti-Pesenti (2001a) setup is smaller than in the benchmark economy. The difference ranges between .0833 when $\omega^{R}=1.2$, .375 when $\omega^{R}=4$, and .5 when $\omega^{R}=1,000,000$. As in Baxter and Crucini (1995), permanent productivity shocks result in much larger differences in responses between complete and incomplete markets.

The labor effort does not respond to the productivity shock in the benchmark economy and in the Corsetti-Pesenti setup. (For this reason, Figure 8.c shows only the response for the complete markets economy with $\omega=\omega^{R}$.) Thus, the Corsetti-Pesenti setup does not result in any error in the characterization of labor effort if the productivity shock is permanent. In both the benchmark economy and the $\omega=1$-approximation, consumption moves just as much as GDP, and agents exactly consume the real value of the permanent increase in productivity in all periods without altering their labor effort relative to the steady state. Consumption rises by less in the CorsettiPesenti setup because home's terms of trade deteriorate by more, which causes the real value of domestic output to increase by less as a consequence of the shock. ${ }^{57}$ Agents increase their supply of

\footnotetext{
${ }^{57}$ The results in Appendix B make it possible to verify that the impact deterioration of the terms of trade in the Corsetti-Pesenti setup is always equal to the size of the shock (1 percent), regardless of its persistence. When
} 
labor effort under complete markets. They do so by more the higher the value of $\omega^{R}$. To understand this, observe that higher substitutability across domestic and foreign goods makes smaller terms of trade movements necessary to keep international goods market equilibrium after shocks. Thus, the higher $\omega^{R}$, the smaller the response of the terms of trade to the shock. At the same time, the higher $\omega^{R}$, the larger the positive impact of any given terms of trade deterioration on domestic labor demand. When $\omega^{R}$ is close to 1 , the complete markets economy behaves very similarly to the Corsetti-Pesenti scenario. Relative price movements are such that labor effort moves by very little. Regardless of $\omega^{R}$, domestic and foreign consumption levels are equal to average world productivity, as in the Corsetti-Pesenti scenario. But $\omega^{R} \neq 1$ implies that employment and GDP levels now differ across countries-and consumption and GDP can differ in each country. To keep consumption constant at the $\omega=1$-level in both countries in a situation in which goods are more highly substitutable, domestic output must increase by more than in the $\omega=1$-scenario, foreign output must increase by less (or even decrease if $\omega^{R}$ is sufficiently high). For this reason, domestic labor demand increases after the shock, foreign labor demand falls, the more so the higher the value of $\omega^{R}$. Thus, the difference in the characterization of the employment response to a permanent shock between the complete markets case and the benchmark scenario, which is larger than for a non-permanent shock even for $\omega^{R}$ close to 1 , becomes substantially wider as goods become better substitutes across countries. Similar conclusions hold for GDP responses: The Corsetti-Pesenti approximation underestimates the response of GDP to the shock. Complete markets overestimate the response. The errors are larger than for non-permanent shocks and become more significant if $\omega^{R}$ increases. Finally, it should be noted that, if $\omega^{R} \rightarrow \infty$, no deterioration in the terms of trade following the shock and no adjustment in labor effort result in consumption and GDP increases by the same amount as the productivity shock under the benchmark specification.

\subsection{Non-Zero Steady-State Net Foreign Assets}

Ghironi, İşcan, and Rebucci (2003) extend the model of this paper to allow for non-zero steadystate net foreign assets, consistent with the evidence in Lane and Milesi-Ferretti (2001, $2002 a, b)$. This is accomplished by assuming that households in the two countries have different discount factors and steady-state levels of productivity can differ across countries. ${ }^{58}$ Non-zero steady-state net foreign assets have important consequences for the dynamics of the model. When steady-state assets are zero, the impact of the interest burden on previously accumulated debt is lost in the loglinearization of (22). Yet, interest payments on existing debt matter a great deal in international

the shock is permanent, $\mathrm{RP}^{D}$ falls permanently by 1 percent. As Corsetti and Pesenti point out, terms of trade adjustment is the centerpiece of international interdependence in their model.

${ }^{58}$ Different discount factors are enough to generate non-zero steady-state net foreign assets. Differences in steadystate productivities are introduced for empirical purposes. See also Buiter (1981) and Weil (1989b). 
interdependence, as suggested by Lane (2002). Allowing for non-zero steady-state assets makes it possible to preserve the effect of the interest burden on debt in the log-linear model. Indeed, it implies that the risk-free world interest rate becomes an additional state variable in the solution. As demonstrated in Ghironi, Isscan, and Rebucci (2003), the solution of the model with non-zero steady-state net foreign assets can be written as:

$$
\begin{aligned}
\mathrm{B}_{t+1} & =\eta_{B B} \mathrm{~B}_{t}+\eta_{B r} \mathrm{r}_{t}+\eta_{B Z} \mathrm{Z}_{t}+\eta_{B Z^{*}} \mathrm{Z}_{t}^{*}, \\
\mathrm{r}_{t+1} & =\eta_{r B} \mathrm{~B}_{t}+\eta_{r r} \mathrm{r}_{t}+\eta_{r Z} \mathrm{Z}_{t}+\eta_{r Z^{*}} \mathrm{Z}_{t}^{*}, \\
\mathrm{x}_{t} & =\eta_{x B} \mathrm{~B}_{t}+\eta_{x r} \mathrm{r}_{t}+\eta_{x Z} \mathrm{Z}_{t}+\eta_{x Z^{*}} \mathrm{Z}_{t}^{*}, \\
\mathrm{x}_{t}^{*} & =\eta_{x^{*} B} \mathrm{~B}_{t}+\eta_{x^{*} r} \mathrm{r}_{t}+\eta_{x^{*} Z} \mathrm{Z}_{t}+\eta_{x^{*} Z^{*}} \mathrm{Z}_{t}^{*}
\end{aligned}
$$

where $\left\{x_{t}, x_{t}^{*}\right\}$ is any pair of endogenous variables in the model other than net foreign assets and the interest rate. (It is no longer possible to separate cross-country differences and world aggregates in the solution of the model and obtain solutions for individual country variables as in Section 4.4.) Non-zero steady-state net foreign assets introduce an additional channel through which the past history of the economy matters for current dynamics relative to the model with zero steadystate assets. The effect of net foreign asset accumulation on cross-country differentials is amplified. Figure 9 shows impulse responses for a calibration of the extended model in which domestic agents have discount factor $\beta$ and foreign agents have discount factor $\alpha \beta$, with $\alpha=.999$. (The value of $\alpha$ is very close to 1 because even small differences in discount factors across countries generate large steady-state asset positions. I choose $\alpha$ close to 1 to minimize the risk of overstating the effect of interest payments on non-zero long-run asset positions.) I assume $\bar{Z}=\bar{Z}^{*}=1$. Other parameter values are as in the benchmark case above: $\beta=.99, \omega=1.2, a=.5, \rho=.33, n=.01 .59$

The relatively small difference between impulse responses of the model in this paper and those of the complete markets economy for $\phi<1$ was motivated by the fact that net foreign asset accumulation had a small impact on cross-country differentials. Figure 9 sheds light on the impact of non-zero steady-state net foreign assets on the responses to shocks. Figure 9. a presents impulse responses at home and abroad following a home productivity shock with no persistence. ${ }^{60}$ Figure $9 . b$ repeats the exercise for $\phi=.75$. Comparison of figures 9 and 1 shows a sizable amplification effect of interest payments on cross-country differentials, especially on the consumption differential.

\footnotetext{
${ }^{59}$ The steady state is such that $\bar{B}>0\left(\bar{B}^{*}<0\right), \bar{c}>\bar{c}^{*}, \bar{L}<\bar{L}^{*}, \bar{w}>\bar{w}^{*}, \overline{R P}>\overline{R P}^{*}, \bar{y}<\bar{y}^{*}$. Domestic agents are more patient than foreign and accumulate steady-state assets, which make it possible to sustain relatively higher consumption with a smaller labor effort. Lower labor supply generates a higher equilibrium real wage and relative price. The labor effort differential prevails on the relative price differential in generating lower GDP at home than abroad, where higher GDP is required to pay interest on the accumulated debt.

${ }^{60}$ Percentage deviations of net foreign assets from the steady state are now defined as $\mathrm{B}_{t} \equiv \frac{d B_{t}}{\bar{B}}$ and $\mathrm{B}_{t}^{*} \equiv \frac{d B_{t}^{*}}{\bar{B}^{*}}$, where the latter is to be interpreted as the deviation of foreign debt from the steady state. Equilibrium requires $\mathrm{B}_{t}=\mathrm{B}_{t}^{*}$. In Figure 9, B1 denotes the deviation of net foreign assets from the steady state at the end of the period.
} 
(Figure 9 presents responses of home and foreign variables for ease of interpretation. The size of implied cross-country differentials for comparison with Figure 1 is easy to gauge.) I refer the reader to Ghironi, İşcan, and Rebucci (2003) for a detailed interpretation of the results of the model with asymmetric steady state. Here, I observe that, interestingly, the home economy runs down its net foreign assets in Figure 9 after an initial small increase, before the economy returns to the steady state. The reason is that the shock causes the foreign terms of trade (not shown) to appreciate sufficiently, and so the consumption value of foreign output (i.e., foreign GDP) to increase enough, that the foreign economy can take advantage of this and of a lower interest rate to reduce its debt below the steady state, while at the same time enjoying higher consumption, consistent with its relative impatience. As a consequence of these effects, the differential $c_{t}-c_{t}^{*}$ is negative in response to the shock, in contrast to Figure 1. The behavior of net foreign assets implies that home consumption falls below the steady state as productivity returns close to 1, again in contrast to what happens in the symmetric steady-state model. Lower home assets (foreign debt) generate less interest income for home agents to spend on consumption, and therefore lower consumption, for the parameter values above.

Comparing figures $9 . b$ and 5 shows that non-zero steady-state net foreign assets amplify the difference between the dynamics of the model economy of this paper and those of the benchmark complete markets economy with zero initial net wealth that is so common in the literature. Ghironi, İscan, and Rebucci (2003) show that non-zero long-run net foreign asset positions result in realistic, asymmetric responses to world productivity shocks in the home and foreign economies and in net foreign asset movements that are not predicted by the standard model with zero steady-state assets, according to which the current account reacts only to relative shocks. If one believes that markets are incomplete and long-run net foreign asset positions are not zero, Figure 9 suggests that complete markets cum zero initial net assets may not be a good approximation of reality. ${ }^{61}$

\section{Conclusions}

I developed a tractable model of macroeconomic interdependence under incomplete markets that solves the well known stationarity problem of several open economy models while preserving a role for the current account and asset accumulation in the transmission of exogenous shocks.

The model builds on Obstfeld and Rogoff's (1995a, 1996 Ch. 10) work, but also on the international RBC literature, exemplified by Baxter and Crucini (1995). In the models of macroeconomic

\footnotetext{
${ }^{61}$ As hinted above, a problem with the model briefly discussed in this subsection is that even small differences between discount factors in the two countries such as that in the parameterization above result in steady-state net foreign assets (or debt) that are significantly larger than 100 percent of GDP, possibly amplifying the effect of interest rate payments beyond what is realistic. Thus, the relevance of the channel discussed here should not be overstated quantitatively in a model without physical capital.
} 
interdependence under incomplete markets presented in those papers, the steady-state distribution of asset holdings across countries is not determined endogenously. The initial position of the world economy for the purpose of log-linearizing and analyzing the consequences of shocks is treated as an exogenous parameter and chosen as a matter of analytical convenience. It is a point to which the economies never return following disturbances, regardless of their temporary or permanent nature. The distribution of asset holdings changes permanently when shocks happen because countries cannot fully insure against the disturbances, and there is no mechanism that generates a return to the original position. In such frameworks, one must be wary when analyzing the results of simulations that extend beyond a short horizon, as variables are wandering away from a point to which they will never return. This may generate spurious results, as wealth transfers across countries triggered by shocks are always permanent, even if shocks are not. In a stochastic setting, this implies that the unconditional variances of endogenous shocks are infinite, even if the shocks are bounded. In a perfect foresight setting that is used to analyze the consequences of different shocks (say, productivity and demand shocks), nothing ensures that the initial position should be the same across shocks. If we think of these surprises as happening at different points in time, the initial position for the second shock will differ from that for the first, which should imply an altogether different set of log-linear equations.

The model of this paper endogenously pins down the steady-state distribution of asset holdings across countries in a world of incomplete markets. A (small) departure from Ricardian equivalence in an overlapping generations framework is sufficient to generate determinacy of the steady state and stationarity. Following non-permanent shocks, the world economy returns to the original steady state. This makes it possible to log-linearize the model knowing that departures from the steady state generated by non-permanent shocks are temporary, implying a significant improvement in the reliability of the log-linear approximation.

The model offers a reasonable explanation for the inability of statistical tests to reject the hypothesis of a unit root in net foreign asset series. Standard tests on relatively short data series may fail to detect stationarity simply because the speed at which assets return to the steady state after a shock is very low, as the model suggests it is for realistic parameter values. At the same time, stationary net foreign assets around a long-run position-that need not be zero-are easier to reconcile with the idea of sustainability of a country's foreign debt position.

Models that circumvent the stationarity issue by shutting off the current account or relegating net foreign assets to a secondary role (assuming unitary intratemporal elasticity of substitution between domestic and foreign goods in consumption and/or complete asset markets) can miss important positive features of the economy if this is (more realistically) characterized by incomplete financial markets and an elasticity of substitution that differs from one. These models fall short of 
explaining key features of recent empirical evidence for the U.S. and other economies. A number of authors have observed that market incompleteness per se is not sufficient for models to replicate quantitative features of international business cycles. (See, for example, Chari, Kehoe, and McGrattan, 2002.) Yet, several scholars have pointed out that incomplete markets are necessary for models to explain important puzzles in international macroeconomics. (Among others, Corsetti, Dedola, and Leduc, 2002; Duarte and Stockman, 2001.) Once one decides to work with an incomplete markets model for realistic quantitative analysis, reliability of the solution requires addressing the model stationarity issue. The model of this paper illustrates an approach for doing so that is alternative to other devices explored in the recent literature. The model provides the starting point for building a theoretical framework that can be used to explain recent dynamics for the U.S. and other economies and for answering a number of policy questions. It is a starting toolkit for reconsidering several results of the literature on international RBC. Including investment and accumulation of physical capital in the analysis will allow a better comparison of results. Once nominal rigidity and a role for monetary policy are introduced, the results of this paper call for re-thinking the findings of several recent studies on monetary policy in open economy that de-emphasize asset accumulation. $^{62}$

\section{Appendix A. Asset Accumulation in the Initial Period}

The no-arbitrage condition (5) will be generally violated when agents are surprised by an initial, unexpected shock at time $t_{0}$. (In a stochastic, rational expectations model, the condition would involve expectations that may be incorrect ex post.) Equations (22) hold in all periods after the initial shock, but may not hold at time $t_{0}$, because unexploited arbitrage opportunities may exist between $t_{0}-1$ and $t_{0}$. This appendix shows that this issue does not poses problems in this paper. Focus on the home economy. Without using (5) between $t_{0}-1$ and $t_{0}$, the dynamics of (aggregate per capita) consumer assets in the initial period are described by:

$$
(1+n)\left(B_{t_{0}+1}+V_{t_{0}}\right)=\left(1+r_{t}\right) B_{t_{0}}+d_{t_{0}}+(1+n) V_{t_{0}}+w_{t_{0}} L_{t_{0}}-c_{t_{0}}
$$

It is: $d_{t_{0}}=(1-\tau) y_{t_{0}}+T_{t_{0}}-w_{t_{0}} L_{t_{0}}$, and $T_{t_{0}}=\tau y_{t_{0}}$. Hence,

$$
(1+n) B_{t_{0}+1}=\left(1+r_{t}\right) B_{t_{0}}+y_{t_{0}}-c_{t_{0}}
$$

\footnotetext{
${ }^{62}$ See Cavallo and Ghironi (2002) for a version of the model that incorporates money and nominal rigidity. Ghironi (2000) develops a small open economy version with nominal rigidity and investment in physical capital. Benigno P. $(2001 b)$ evaluates the gains from international monetary coordination in a representative agent, stationary, incomplete markets world.
} 
But this is the same equation as in (22). In particular, because $B_{t_{0}}$ was determined at time $t_{0}-1$, when the economy was in steady state, $B_{t_{0}}=0$. Thus,

$$
(1+n) B_{t_{0}+1}=y_{t_{0}}-c_{t_{0}}
$$

This is the same equation that is obtained from the law of motion for domestic net foreign assets in (22) by setting $B_{t_{0}}=0$. $B_{t_{0}+1}^{*}$ is determined by $-\frac{a}{1-a} B_{t_{0}+1}$.

\section{Appendix B. Solving the Model with the Method of Undetermined Coefficients}

This appendix describes the undetermined coefficients solution of model for cross-country differences. The solution makes it possible to explore the role of changes in relative country size for interdependence across countries.

Equations (55) and (53) can be rewritten as follows:

$$
\begin{aligned}
0= & -(1+n)[1+\rho(\omega-1)] \frac{\mathrm{B}_{t+1}}{1-a}+[1-\rho+\beta \rho \omega] \frac{1}{\beta} \frac{\mathrm{B}_{t}}{1-a}-\omega \mathrm{h}_{t}^{D}+(\omega-1) \mathrm{Z}_{t}^{D}, \\
0= & -[\rho \omega+\beta(1-\rho)] \mathrm{h}_{t}^{D}+(1-\beta)(1-\rho) \rho \frac{1-\beta}{\beta} \frac{\mathrm{B}_{t}}{1-a} \\
& +(1-\beta) \rho(\omega-1) \mathrm{Z}_{t}^{D}+\beta[1+\rho(\omega-1)] \mathrm{h}_{t+1}^{D} .
\end{aligned}
$$

Conjecture the solution:

$$
\begin{aligned}
\frac{\mathrm{B}_{t+1}}{1-a} & =\widetilde{\eta}_{B B} \frac{\mathrm{B}_{t}}{1-a}+\widetilde{\eta}_{B Z^{D}} \mathrm{Z}_{t}^{D} \\
\mathrm{~h}_{t}^{D} & =\widetilde{\eta}_{h^{D} B} \frac{\mathrm{B}_{t}}{1-a}+\widetilde{\eta}_{h^{D} Z^{D}} \mathrm{Z}_{t}^{D} .
\end{aligned}
$$

Conjecture (73)-(74) is isomorphic to equations (56)-(57) in the text, with $\eta_{B B}=\widetilde{\eta}_{B B}, \eta_{B Z^{D}}=$ $(1-a) \widetilde{\eta}_{B Z^{D}}, \eta_{h^{D} B}=\frac{\widetilde{\eta}_{h^{D}}}{1-a}$, and $\eta_{h^{D} Z^{D}}=\widetilde{\eta}_{h^{D} Z^{D}}$. To obtain solutions for the elasticities $\widetilde{\eta}_{B B}$, $\widetilde{\eta}_{B Z^{D}}, \widetilde{\eta}_{h^{D} B}$, and $\widetilde{\eta}_{h^{D} Z^{D}}$, proceed as follows. Substitute the conjecture (73)-(74) into (71) and (72):

$$
\begin{aligned}
& 0=-(1+n)[1+\rho(\omega-1)]\left(\widetilde{\eta}_{B B} \frac{\mathrm{B}_{t}}{1-a}+\widetilde{\eta}_{B Z^{D}} \mathrm{Z}_{t}^{D}\right)+[1-\rho+\beta \rho \omega] \frac{1}{\beta} \frac{\mathrm{B}_{t}}{1-a} \\
& -\omega\left(\widetilde{\eta}_{h^{D} B} \frac{\mathrm{B}_{t}}{1-a}+\widetilde{\eta}_{h^{D} Z^{D}} \mathrm{Z}_{t}^{D}\right)+(\omega-1) \mathrm{Z}_{t}^{D}, \\
& 0=-[\rho \omega+\beta(1-\rho)]\left(\widetilde{\eta}_{h^{D} B} \frac{\mathrm{B}_{t}}{1-a}+\widetilde{\eta}_{h^{D} Z^{D}} \mathrm{Z}_{t}^{D}\right)+(1-\beta)(1-\rho) \rho \frac{1-\beta}{\beta} \frac{\mathrm{B}_{t}}{1-a} \\
& +(1-\beta) \rho(\omega-1) \mathbf{Z}_{t}^{D}+\beta[1+\rho(\omega-1)]\left[\widetilde{\eta}_{h^{D} B}\left(\widetilde{\eta}_{B B} \frac{\mathrm{B}_{t}}{1-a}+\widetilde{\eta}_{B Z^{D}} \mathbf{Z}_{t}^{D}\right)+\widetilde{\eta}_{h^{D} Z^{D}} \phi \mathbf{Z}_{t}^{D}\right]
\end{aligned}
$$

where I have made use of $Z_{t+1}^{D}=\phi Z_{t}^{D}$ in the second equation. 
Now equate the coefficients on $\frac{\mathrm{B}_{t}}{1-a}$ :

$$
\begin{aligned}
& 0=-(1+n)[1+\rho(\omega-1)] \widetilde{\eta}_{B B}+[1-\rho+\beta \rho \omega] \frac{1}{\beta}-\omega \widetilde{\eta}_{h^{D} B}, \\
& 0=-[\rho \omega+\beta(1-\rho)] \widetilde{\eta}_{h^{D} B}+(1-\beta)(1-\rho) \rho \frac{1-\beta}{\beta}+\beta[1+\rho(\omega-1)] \widetilde{\eta}_{h^{D} B} \widetilde{\eta}_{B B} .
\end{aligned}
$$

The first relation implies:

$$
\widetilde{\eta}_{h^{D} B}=-(1+n) \frac{1+\rho(\omega-1)}{\omega} \widetilde{\eta}_{B B}+\frac{1-\rho+\beta \rho \omega}{\beta \omega} .
$$

Substituting into the second relation, we obtain a second order polynomial in $\widetilde{\eta}_{B B}$ :

$$
\begin{aligned}
0= & \{[\rho \omega+\beta(1-\rho)](1+n)+1-\rho+\beta \rho \omega\} \frac{1+\rho(\omega-1)}{\omega} \widetilde{\eta}_{B B} \\
& +(1-\beta)(1-\rho) \rho \frac{1-\beta}{\beta}-[\rho \omega+\beta(1-\rho)] \frac{1-\rho+\beta \rho \omega}{\beta \omega} \\
& -\beta[1+\rho(\omega-1)](1+n) \frac{1+\rho(\omega-1)}{\omega} \widetilde{\eta}_{B B}^{2} \\
\equiv & \Gamma\left(\widetilde{\eta}_{B B}\right)
\end{aligned}
$$

Further manipulation makes it possible to simplify the polynomial as:

$$
\begin{aligned}
\Gamma\left(\widetilde{\eta}_{B B}\right)= & \left\{(1+\beta+n) \frac{[1+\rho(\omega-1)]^{2}}{\omega}-n(1-\rho)(1-\beta) \frac{[1+\rho(\omega-1)]}{\omega}\right\} \widetilde{\eta}_{B B} \\
& -\frac{[1+\rho(\omega-1)]^{2}}{\omega}-\beta(1+n) \frac{[1+\rho(\omega-1)]^{2}}{\omega} \widetilde{\eta}_{B B}^{2} .
\end{aligned}
$$

Note that:

$$
\begin{aligned}
\Gamma( \pm \infty) & =-\infty, \\
\Gamma(0) & =-\frac{[1+\rho(\omega-1)]^{2}}{\omega}<0, \\
\Gamma(1) & =n(1-\beta) \rho[1+\rho(\omega-1)]>0, \\
\Gamma\left(\frac{1}{\beta}\right) & =-n(1-\rho) \frac{1-\beta}{\beta} \frac{[1+\rho(\omega-1)]}{\omega}<0 .
\end{aligned}
$$

Hence, the polynomial $\Gamma\left(\widetilde{\eta}_{B B}\right)$ has two roots: one between 0 and 1 and one between 1 and $\beta^{-1}$ (uninteresting). Once the stable root $\widetilde{\eta}_{B B} \in(0,1)$ has been obtained by solving the quadratic equation $\Gamma\left(\widetilde{\eta}_{B B}\right)=0, \widetilde{\eta}_{h^{D} B}$ follows from (75). For $\widetilde{\eta}_{h^{D} B}$ to be positive, it must be $\widetilde{\eta}_{B B}<$ $\frac{1-\rho+\beta \rho \omega}{\beta(1+n)[1+\rho(\omega-1)]}$, which is satisfied for plausible parameter values.

Turning to the coefficients on $Z_{t}^{D}$, we have:

$$
\begin{aligned}
& 0=-(1+n)[1+\rho(\omega-1)] \widetilde{\eta}_{B Z^{D}}-\omega \widetilde{\eta}_{h^{D} Z^{D}}+\omega-1, \\
& 0=-[\rho \omega+\beta(1-\rho)] \widetilde{\eta}_{h^{D} Z^{D}}+(1-\beta) \rho(\omega-1)+\beta[1+\rho(\omega-1)]\left(\widetilde{\eta}_{h^{D} B} \widetilde{\eta}_{B Z^{D}}+\widetilde{\eta}_{h^{D} Z^{D}} \phi\right),
\end{aligned}
$$


from which we obtain:

$$
\begin{aligned}
\widetilde{\eta}_{B Z^{D}} & =\frac{\beta(\omega-1)(1-\phi)}{(1+n)\{\rho \omega+\beta(1-\rho)-\beta \phi[1+\rho(\omega-1)]\}+\beta \omega \widetilde{\eta}_{h^{D} B}}, \\
\widetilde{\eta}_{h^{D} Z^{D}} & =-(1+n) \frac{[1+\rho(\omega-1)]}{\omega} \widetilde{\eta}_{B Z^{D}}+\frac{\omega-1}{\omega} .
\end{aligned}
$$

Both these elasticities are positive for a broad range of sensible parameter values.

Inspection of the results obtained thus far shows that the solutions for $\widetilde{\eta}_{B B}, \widetilde{\eta}_{B Z^{D}}, \widetilde{\eta}_{h^{D} B}$, and $\widetilde{\eta}_{h^{D} Z^{D}}$ are not affected by changes in the relative size of the two countries. Because $\eta_{B B}$ and $\eta_{h^{D} Z^{D}}$ in equations (56)-(57) are equal to $\widetilde{\eta}_{B B}$ and $\widetilde{\eta}_{h^{D} Z^{D}}$, respectively, the elasticity of aggregate per capita net foreign assets to its past level and the elasticity of the human wealth differential to the productivity differential are not affected by country size. This is so because $\eta_{B B}$ relates a domestic variable to itself and $\eta_{h^{D} Z^{D}}$ relates a cross-country differential to another. By definition, relative country size must be irrelevant for these elasticities. Instead, $\eta_{B Z^{D}}=(1-a) \widetilde{\eta}_{B Z^{D}}$ and $\eta_{h^{D} B}=\frac{\widetilde{\eta}_{h D_{B}}}{1-a}$ imply that the elasticity of asset accumulation to the productivity differential and of the human wealth differential to net foreign assets change with country size. The larger the domestic economy (the closer $a$ to 1 ), the smaller the elasticity of net assets to the productivity differential. Intuitively, a productivity differential relative to a foreign economy of negligible size $(a \rightarrow 1)$ has no effect on the home economy's incentive to accumulate or decumulate assets. The elasticity of the human wealth differential to net foreign assets is smaller the smaller the home economy (the closer $a$ to 0$)$. If home is a small open economy $(a \rightarrow 0)$, a given productivity differential relative to foreign causes a larger movement in domestic aggregate per capita net foreign assets. To keep a given, desired smoothness of the consumption path following a larger reaction of assets to the shock, $\eta_{h^{D} B}$ must fall.

Given solutions for $\eta_{B B}, \eta_{B Z^{D}}, \eta_{h^{D} B}$, and $\eta_{h^{D} Z^{D}}$, it is easy to recover the other relevant elasticity parameters from the equations in Section 4. In what follows, I assume that parameter values are such that $\eta_{B B}, \eta_{B Z^{D}}, \eta_{h^{D} B}$, and $\eta_{h^{D} Z^{D}}$ are all positive and $\omega>1$. This is sufficient to be able to sign most elasticities below.

The elasticities of the consumption differential to assets and relative productivity are, respectively:

$$
\eta_{c^{D} B}=\frac{\rho(1-\beta)}{\beta(1-a)}+\eta_{h^{D} B}>0, \quad \eta_{c^{D} Z^{D}}=\eta_{h^{D} Z^{D}}>0 .
$$

As for the real wage and relative price differentials:

$$
\begin{aligned}
\eta_{w^{D} B} & =\frac{1-\rho}{1+\rho(\omega-1)} \eta_{c^{D} B}>0, \quad \eta_{w^{D} Z^{D}}=\frac{1-\rho}{1+\rho(\omega-1)} \eta_{c^{D} Z^{D}}+\frac{\rho(\omega-1)}{1+\rho(\omega-1)}>0, \\
\eta_{R P^{D} B} & =\eta_{w^{D} B}>0, \eta_{R P^{D} Z^{D}}=\eta_{w^{D} Z^{D}}-1<0 .
\end{aligned}
$$


(Plausible parameter values yield $\eta_{w^{D} Z^{D}}<1$.) Finally, the elasticities of the employment and real GDP differentials are:

$$
\begin{aligned}
& \eta_{L^{D} B}=-\omega \eta_{w^{D} B}<0, \eta_{L^{D} Z^{D}}=-\omega \eta_{w^{D} Z^{D}}+\omega-1 \\
& \eta_{y^{D} B}=-(\omega-1) \eta_{w^{D} B}<0, \eta_{y^{D} Z^{D}}=-(\omega-1)\left(\eta_{w^{D} Z^{D}}-1\right)>0 .
\end{aligned}
$$

Given $\eta_{w^{D} Z^{D}}<1, \eta_{L^{D} Z^{D}}>0 \Leftrightarrow \omega\left(1-\eta_{w^{D} Z^{D}}\right)>1$, which holds for plausible parameter values.

\section{Acknowledgments}

I thank Kit Baum, Gianluca Benigno, Pierpaolo Benigno, Charles Carlstrom, Michele Cavallo, Carolyn Evans, Mark Gertler, Peter Ireland, Talan Isscan, Marco Maffezzoli, Lee Ohanian, Paolo Pesenti, Alessandro Rebucci, Eric van Wincoop, and participants in a seminar at the University of Québec at Montréal for helpful conversations and comments. I am especially grateful to Cédric Tille for pointing out an error in a previous draft and for a number of extremely helpful comments. I thank IGIER-Bocconi University for the warm hospitality in June 2000, when the first draft of this paper was written. A significant portion of the subsequent work was undertaken while I was at the Federal Reserve Bank of New York. I gratefully acknowledge financial support from Boston College through a 2001 Summer-Fall Research Expense Grant and through the Richard W. Tresch Economics Junior Faculty Fund. Petronilla Nicoletti provided excellent research assistance. All remaining errors are of course mine.

\section{References}

[1] Asdrubali, P., B. Sørensen, and O. Yosha (1996): "Channels of Interstate Risk Sharing: United States 1963-90," Quarterly Journal of Economics 111: 1081-1110.

[2] Atkeson, A., and T. Bayoumi (1993): "Do Private Capital Markets Insure Regional Risk? Evidence from the United States and Europe," Open Economies Review 4: 303-324.

[3] Baxter, M., and M. Crucini (1995): "Business Cycles and the Asset Structure of Foreign Trade," International Economic Review 36: 821-853.

[4] Bayoumi, T., and M. Klein (1997): "A Provincial View of Economic Integration," International Monetary Fund Staff Papers 44: 534-556.

[5] Becker, R. A. (1980): "On the Long-Run Steady State in a Simple Dynamic Model of Equilibrium with Heterogeneous Households," Quarterly Journal of Economics 95: 375-382. 
[6] Benigno, G. (1999): "Real Exchange Rate Persistence with Endogenous Monetary Policy," unpublished manuscript, London School of Economics.

[7] Benigno, G., and P. Benigno (2001): "Monetary Policy Rules and the Exchange Rate," CEPR DP 2807.

[8] Benigno, P. (2001a): "Optimal Monetary Policy in a Currency Area," CEPR DP 2755.

[9] Benigno, P. (2001b): "Price Stability with Imperfect Financial Integration," unpublished manuscript, New York University.

[10] Blanchard, O. J. (1985): "Debt, Deficits, and Finite Horizons," Journal of Political Economy 93: 223-247.

[11] Blanchard, O. J., and C. M. Kahn (1980): "The Solution of Linear Difference Models under Rational Expectations," Econometrica 48: 1305-1311.

[12] Buiter, W. H. (1981): "Time Preference and International Lending and Borrowing in an Overlapping-Generations Model," Journal of Political Economy 89: 769-797.

[13] Campbell, J. Y. (1994): "Inspecting the mechanism: An Analytical Approach to the Stochastic Growth Model," Journal of Monetary Economics 33: 463-506.

[14] Cardia, E. (1991): "The Dynamics of a Small Open Economy in Response to Monetary, Fiscal, and Productivity Shocks," Journal of Monetary Economics 28: 411-434.

[15] Cavallo, M., and F. Ghironi (2001): "Net Foreign Assets and the Exchange Rate: Redux Revived," Journal of Monetary Economics 49: 1057-1097.

[16] Chari, V. V., P. J. Kehoe, and E. R. McGrattan (2002): "Can Sticky Price Models Generate Volatile and Persistent Real Exchange Rates?" Review of Economic Studies 69: 533-563.

[17] Clarida, R. H. (1990): "International Lending and Borrowing in a Stochastic, Stationary Equilibrium," International Economic Review 31: 543-558.

[18] Cole, H. L., and M. Obstfeld (1991): "Commodity Trade and International Risk Sharing: How Much Do Financial Markets Matter?" Journal of Monetary Economics 28: 3-24.

[19] Correia, I., J. C. Neves, and S. Rebelo (1995): "Business Cycles in a Small Open Economy," European Economic Review 39: 1089-1113. 
[20] Corsetti, G., L. Dedola, and S. Leduc (2002): "Understanding the Lack of International RiskSharing: Do Goods Markets Matter?" unpublished manuscript, University of Rome III, Bank of Italy, and Federal Reserve Bank of Philadelphia.

[21] Corsetti, G., and P. Pesenti (2001a): "Welfare and Macroeconomic Interdependence," Quarterly Journal of Economics 116: 421-446.

[22] Corsetti, G., and P. Pesenti (2001b): "International Dimensions of Optimal Monetary Policy," NBER WP 8230.

[23] Crucini, M. (1999): "On International and National Dimensions of Risk Sharing," Review of Economics and Statistics 81: 73-84.

[24] Devereux, M. B. (2003): "A Tale of Two Currencies: The Asian Crisis and the Exchange Rate Regimes of Hong Kong and Singapore," Review of International Economics, forthcoming.

[25] Devereux, M. B., and C. Engel (2000): "Monetary Policy in the Open Economy Revisited: Price Setting and Exchange Rate Flexibility," NBER WP 7665.

[26] Devereux, M. B., and M. Saito (1997): "Growth and Risk-Sharing with Incomplete International Asset Markets," Journal of International Economics 42: 453-481.

[27] Duarte, M., and A. C. Stockman (2001): "Rational Speculation and Exchange Rates," NBER WP 8362.

[28] Feenstra, R. C. (1994): "New Product Varieties and the Measurement of International Prices," American Economic Review 84: 157-177.

[29] Frenkel, J. A., and A. Razin (1987): Fiscal Policies and the World Economy, Cambridge: MIT Press.

[30] Galí, J., and T. Monacelli (2002): "Monetary Policy and Exchange Rate Volatility in a Small Open Economy," CEPR DP 3346.

[31] Ghironi, F. (1999): "Essays on Economic Interdependence," Ph.D. Dissertation, University of California, Berkeley.

[32] Ghironi, F. (2000): "Understanding Macroeconomic Interdependence: Do We Really Need to Shut Off the Current Account?," WP 465, Department of Economics, Boston College. 
[33] Ghironi, F., T. B. İşcan, and A. Rebucci (2003): "Productivity Shocks and Consumption Smoothing in the International Economy," unpublished manuscript, Boston College, Dalhousie University, and International Monetary Fund.

[34] Hamilton, J. D. (1994): Time Series Analysis, Princeton: Princeton University Press.

[35] Harrigan, J. (1993): "OECD Imports and Trade Barriers in 1983," Journal of International Economics 35: 91-111.

[36] Heathcote, J., and F. Perri (2002): "Financial Autarky and International Business Cycles," Journal of Monetary Economics 49: 601-627.

[37] Hummels, D. (1999): "Toward a Geography of Trade Costs," unpublished manuscript, University of Chicago.

[38] Kareken, J., and N. Wallace (1981): "On the Indeterminacy of Equilibrium Exchange Rates," Quarterly Journal of Economics 96: 207-222.

[39] Kehoe, P. J., and F. Perri (2002): "International Business Cycles with Endogenous Incomplete Markets," Econometrica 70: 907-928.

[40] Kim, S. H., and M. A. Kose (2003): "Dynamics of Open Economy Business Cycle Models: Understanding the Role of the Discount Factor," Macroeconomic Dynamics, forthcoming.

[41] Kollmann, R. (2002): "Monetary Policy Rules in the Open Economy: Effects on Welfare and Business Cycles," Journal of Monetary Economics 49: 989-1015.

[42] Lane, P. R. (2001): "The New Open Economy Macroeconomics: A Survey," Journal of International Economics 54: 235-266.

[43] Lane, P. R. (2002): "Comment on: Net Foreign Assets and the Exchange Rate: Redux Revived," Journal of Monetary Economics 49: 1099-1102.

[44] Lane, P. R., and G. M. Milesi-Ferretti (2000): "The Transfer Problem Revisited: Net Foreign Assets and Real Exchange Rates," CEPR DP 2511.

[45] Lane, P. R., and G. M. Milesi-Ferretti (2001): "The External Wealth of Nations: Measures of Foreign Assets and Liabilities for Industrial and Developing Countries," Journal of International Economics 55: 263-294.

[46] Lane, P. R., and G. M. Milesi-Ferretti (2002a): "Long-Term Capital Movements," in Bernanke, B. S., and K. Rogoff (eds.), NBER Macroeconomics Annual 2001, Cambridge: MIT Press. 
[47] Lane, P. R., and G. M. Milesi-Ferretti (2002b): "External Wealth, the Trade Balance, and the Real Exchange Rate," European Economic Review 46: 1049-1071.

[48] Ljungqvist, L., and T. J. Sargent (2000): Recursive Macroeconomic Theory, Cambridge: MIT Press.

[49] McDonald, I. M., and R. S. Guest (2001): "How Uzawa Preferences Improve the Simulation Properties of the Small Open Economy Model," Journal of Macroeconomics 23: 417-440.

[50] Mendoza, E. G. (1991): "Real Business Cycles in a Small Open Economy," American Economic Review 81: 797-818.

[51] Neumeyer, P. A., and F. Perri (1999): "Business Cycles in Emerging Economies: The Role of Country Risk," unpublished manuscript, Universidad T. di Tella and New York University.

[52] Obstfeld, M. (1981a): "Macroeconomic Policy, Exchange-Rate Dynamics, and Optimal Asset Accumulation," Journal of Political Economy 89: 1142-1161.

[53] Obstfeld, M. (1981b): "Capital Mobility and Devaluation in an Optimizing Model with Rational Expectations," American Economic Review Papers and Proceedings 71: 217-221.

[54] Obstfeld, M. (1990): "Intertemporal Dependence, Impatience, and Dynamics," Journal of Monetary Economics 26: 45-75.

[55] Obstfeld, M., and K. Rogoff (1995a): "Exchange Rate Dynamics Redux," Journal of Political Economy 103: 624-660.

[56] Obstfeld, M., and K. Rogoff (1995b): "The Intertemporal Approach to the Current Account," in G. M. Grossman and K. Rogoff (eds.), Handbook of International Economics, Vol. 3, pp.17311799, Amsterdam: North-Holland.

[57] Obstfeld, M., and K. Rogoff (1996): Foundations of International Macroeconomics, Cambridge: MIT Press.

[58] Obstfeld, M., and K. Rogoff (2000): "New Directions for Stochastic Open Economy Models," Journal of International Economics 50: 117-154.

[59] Obstfeld, M., and K. Rogoff (2001): "The Six Major Puzzles in International Macroeconomics: Is There a Common Cause?" in B. Bernanke and K. Rogoff (eds.), NBER Macroeconomics Annual 2000, pp. 339-390, Cambridge: MIT Press. 
[60] Schmitt-Grohé, S., and M. Uribe (2001): "Stabilization Policy and the Costs of Dollarization," Journal of Money, Credit and Banking 33: 482-509.

[61] Schmitt-Grohé, S., and M. Uribe (2003): "Closing Small Open Economy Models," Journal of International Economics, forthcoming.

[62] Shiells, C. R., R. M. Stern, and A. V. Deardorff (1986): "Estimates of the Elasticities of Substitution between Imports and Home Goods for the United States," Weltwirtschaftliches Archiv 122(3): 497-519.

[63] Smets, F., and R. Wouters (1999): "The Exchange Rate and the Monetary Transmission Mechanism in Germany," De Economist.

[64] Smets, F., and R. Wouters (2002): "Openness, Imperfect Exchange Rate Pass-Through and Monetary Policy," Journal of Monetary Economics 49: 947-981.

[65] Sørensen, B., and O. Yosha (1998): "International Risk Sharing and European Monetary Unification," Journal of International Economics 45: 211-238.

[66] Tille, C. (2000): "Is the Integration of World Asset Markets Necessarily Beneficial?," Federal Reserve Bank of New York Staff Report 114.

[67] Tille, C. (2001): "The Role of Consumption Substitutability in the International Transmission of Shocks," Journal of International Economics 53: 421-444.

[68] Trefler, D., and H. Lai (1999): "The Gains from Trade: Standard Errors with the Monopolistic Competition Model," unpublished manuscript, University of Toronto.

[69] Uzawa, H. (1968): "Time Preference, the Consumption Function and Optimum Asset Holdings," in J. N. Wolfe (ed.), Value, Capital and Growth: Papers in Honor of Sir John Hicks, Edinburgh: Edinburgh University Press.

[70] Weil, P. (1987): "Permanent Budget Deficits and Inflation," Journal of Monetary Economics 20: $393-410$.

[71] Weil, P. (1989a): "Overlapping Families of Infinitely-Lived Agents," Journal of Public Economics 38: 183-198.

[72] Weil, P. (1989b): "Money, Time Preference, and External Balance," European Economic Review 33: 564-572.

[73] Weil, P. (1991): "Is Money Net Wealth?," International Economic Review 32: 37-53. 
[74] Yaari, M. E. (1965): "Uncertain Lifetime, Life Insurance, and the Theory of the Consumer," Review of Economic Studies 32: 137-150. 
Table 1. Augmented Dickey-Fuller test, aggregate per capita real net foreign assets Annual data (1 lag)

ADF Statistic Rejection at $5 \%$ ?

$\begin{array}{lcc}\text { Australia } & -3.14653 & \text { No } \\ \text { Canada } & -1.90856 & \text { No } \\ \text { France } & -2.14794 & \text { No } \\ \text { Germany } & -1.58388 & \text { No } \\ \text { Italy } & -1.16713 & \text { No } \\ \text { Japan } & 1.175221 & \text { No } \\ \text { New Zealand } & -2.84448 & \text { No } \\ \text { United Kingdom } & -1.7309 & \text { No } \\ \text { United States } & -1.52505 & \text { No } \\ & & \\ \text { 1\% Critical Value } & -4.4167 & \\ 5 \% \text { Critical Value } & -3.6219 & \\ 10 \% \text { Critical Value } & -3.2474 & \end{array}$

Quarterly data (4 lags)

ADF Statistic Rejection at 5\%?

$\begin{array}{lcc}\text { Australia } & -3.59234 & \text { Yes } \\ \text { Canada } & -1.95337 & \text { No } \\ \text { France } & -1.55332 & \text { No } \\ \text { Germany } & -1.53016 & \text { No } \\ \text { Italy } & -1.57733 & \text { No } \\ \text { Japan } & 1.920747 & \text { No } \\ \text { New Zealand } & -2.58078 & \text { No } \\ \text { United Kingdom } & -2.4575 & \text { No } \\ \text { United States } & -1.15199 & \text { No } \\ & & \\ 1 \% \text { Critical Value } & -4.0602 & \\ 5 \% \text { Critical Value } & -3.4586 & \\ 10 \% \text { Critical Value } & -3.1551 & \end{array}$


Table 2. The benchmark solution, cross-country differences

$$
\mathrm{B}_{t} \quad \mathrm{Z}_{t}^{D}(\phi=0) \quad \mathrm{Z}_{t}^{D}(\phi=.5) \quad \mathrm{Z}_{t}^{D}(\phi=.9) \quad \mathrm{Z}_{t}^{D}(\phi=1)
$$

$\begin{array}{lrrrrr}\mathrm{B}_{t+1} & .9939 & .0923 & .0917 & .0875 & 0 \\ \mathrm{RP}_{t}^{D} & .00691 & -.9374 & -.9368 & -.932 & -.8333 \\ \mathrm{~L}_{t}^{D} & -.0083 & .12493 & .12417 & .1184 & 0 \\ \mathrm{w}_{t}^{D} & .00691 & .06256 & .06319 & .0680 & .16667 \\ \mathrm{y}_{t}^{D} & -.0014 & .18749 & .18736 & .1864 & .16667 \\ \mathrm{c}_{t}^{D} & .01099 & .00102 & .00203 & .00968 & .16667\end{array}$


Figure 1. Impulse responses, net foreign assets and cross-country differences
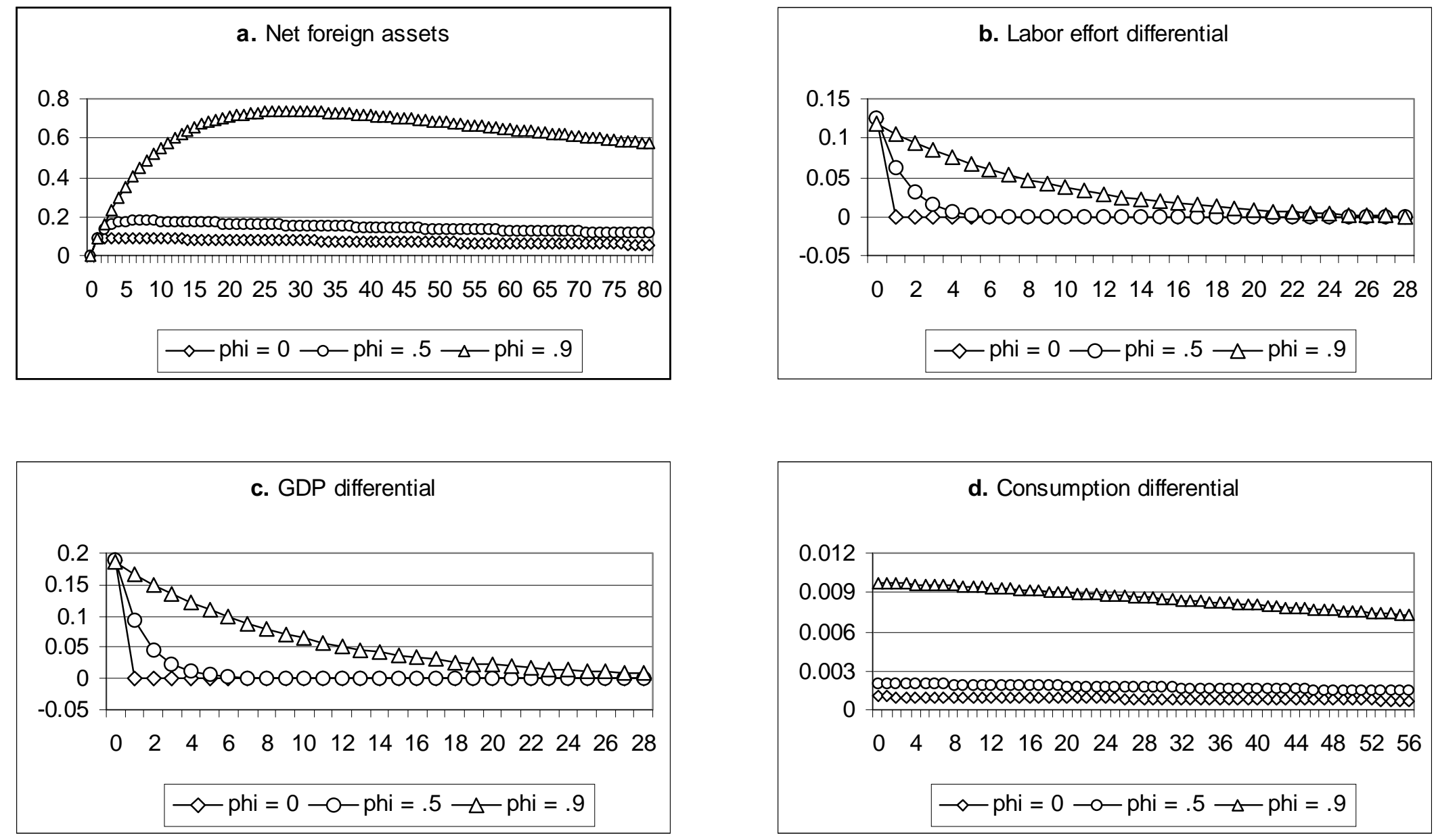
Figure 2. The non-stationary case

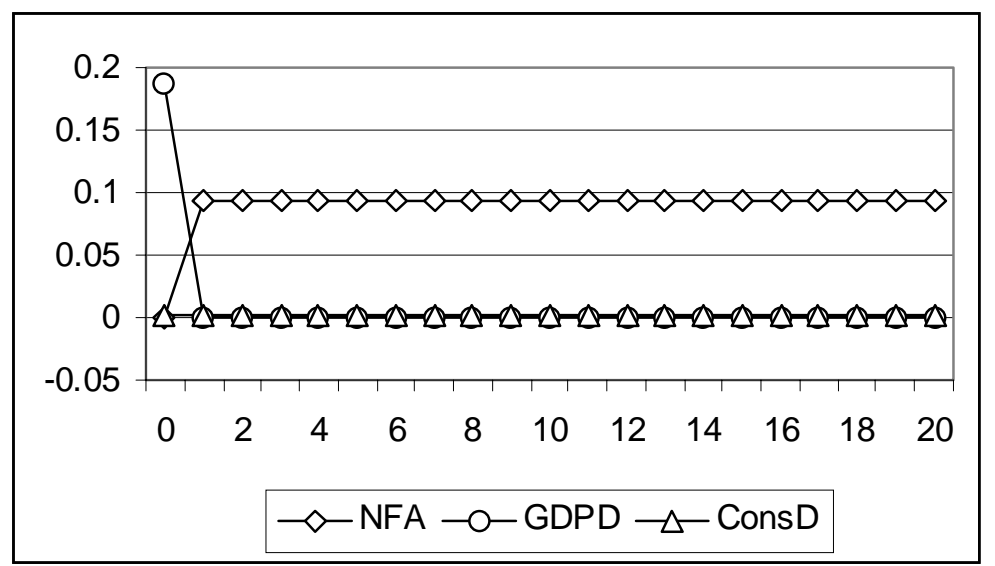

Figure 3. Fast convergence

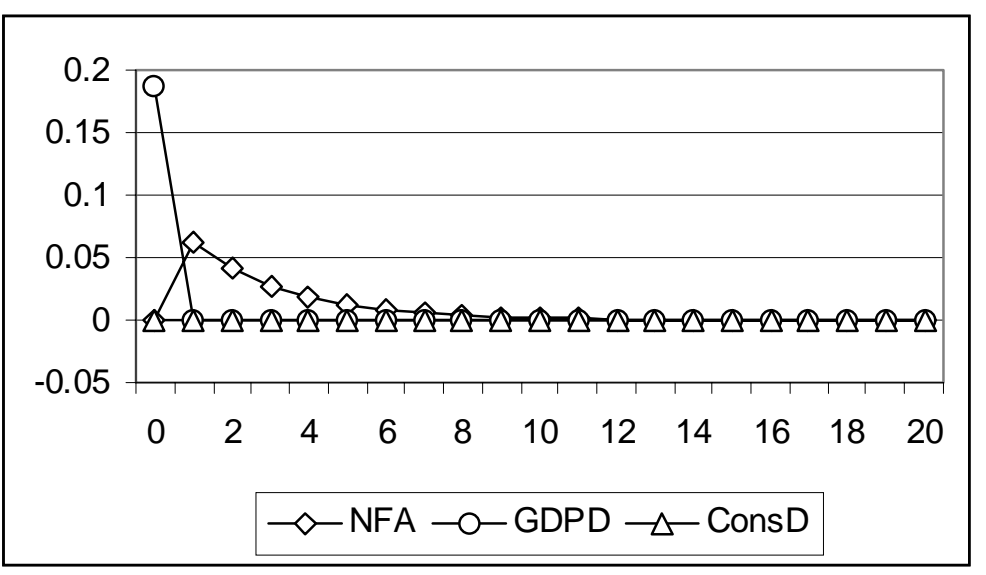

Figure 4. Higher substitutability

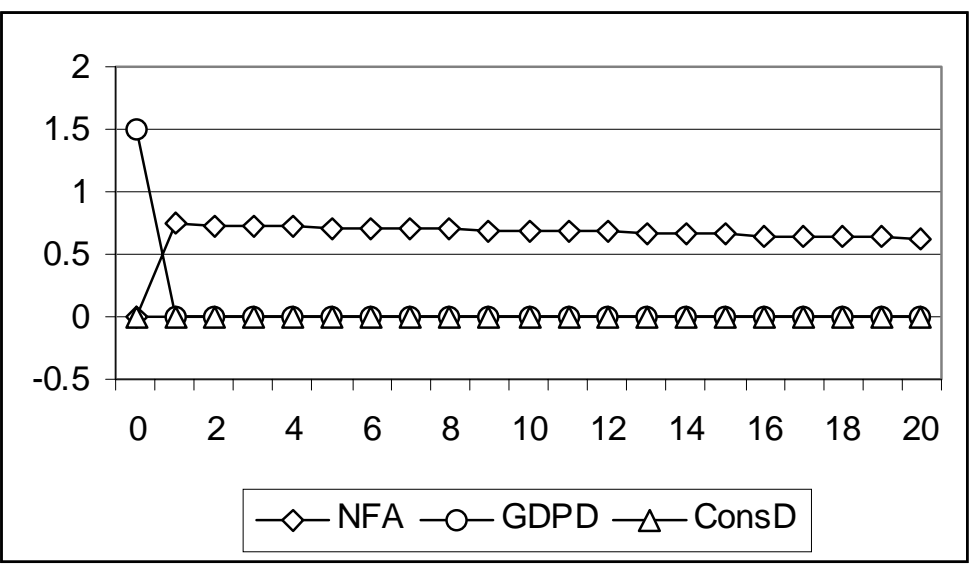


Figure 5. Model comparison, $\phi=.9, \omega^{R}=1.2$
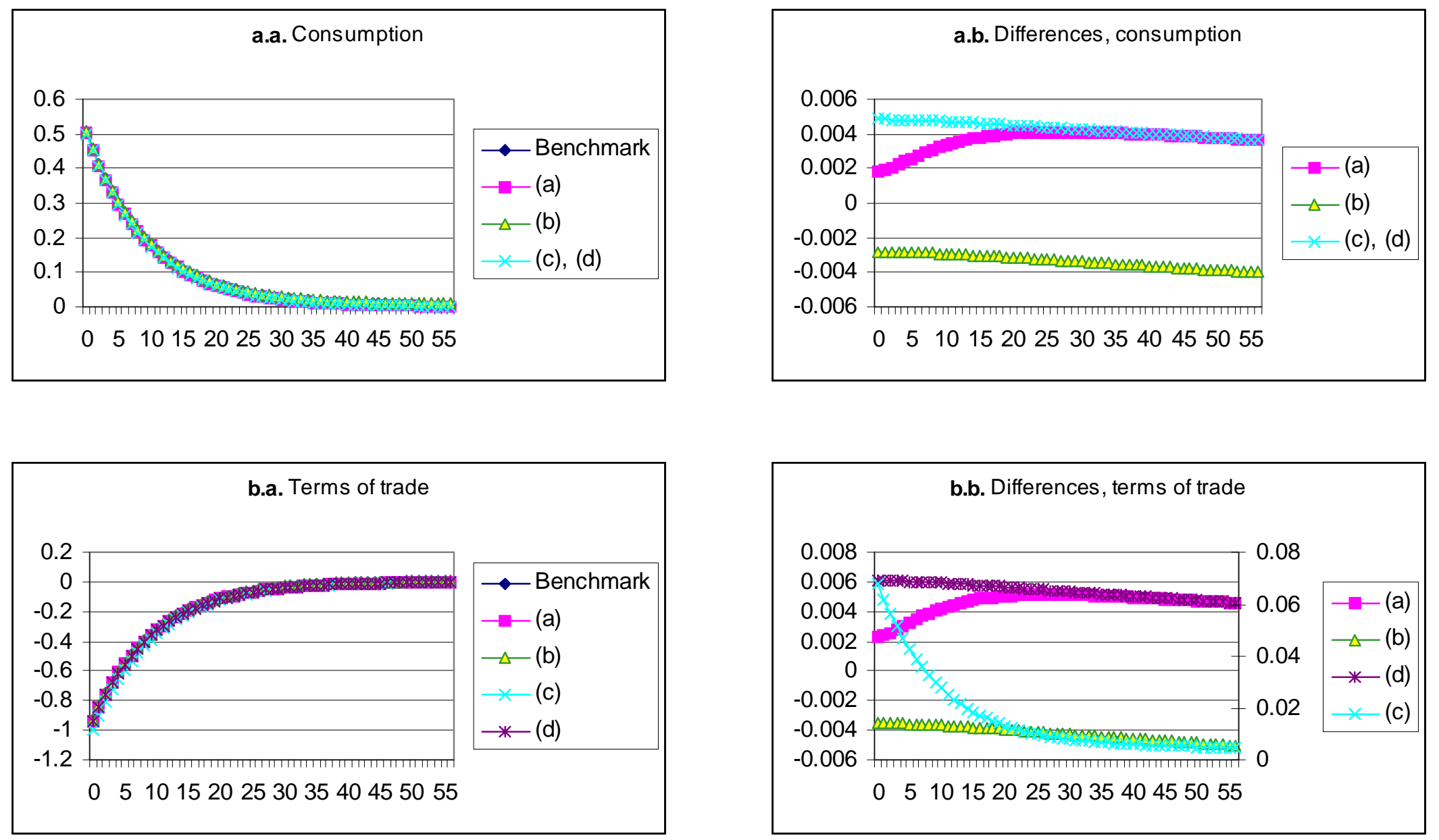
Figure 5, continued
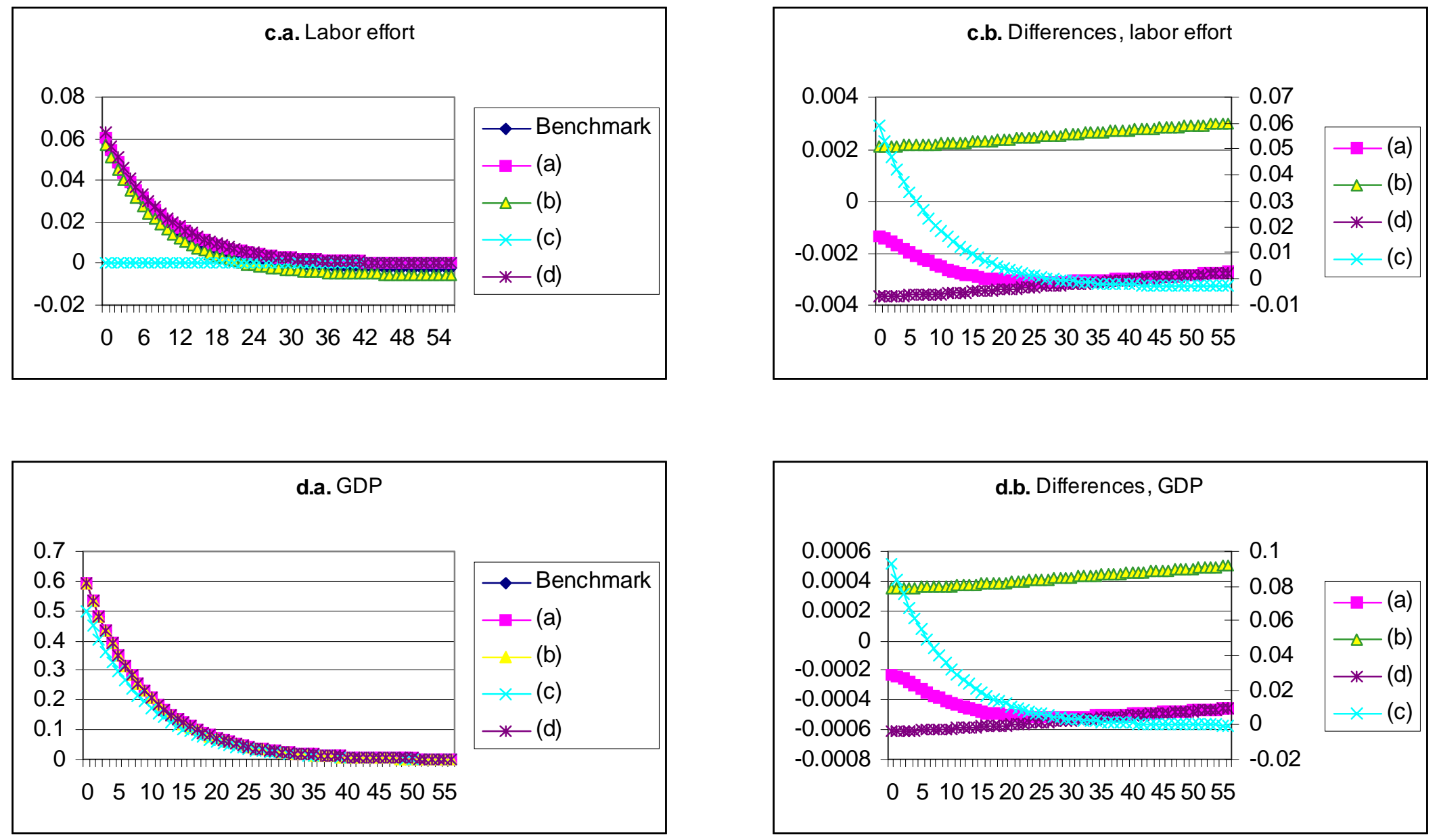
Figure 6. Model comparison, $\phi=.9, \omega^{R}=4$
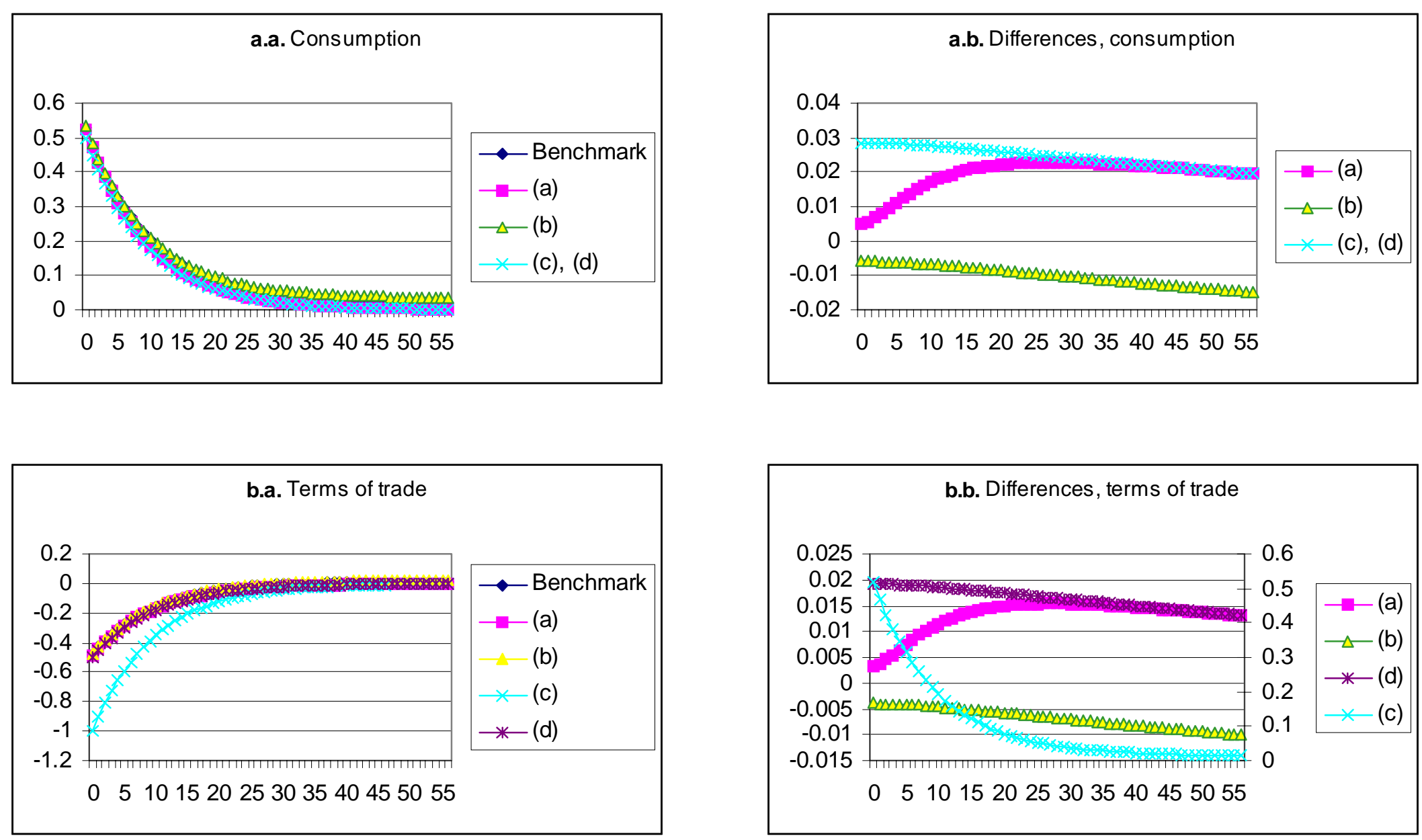
Figure 6, continued
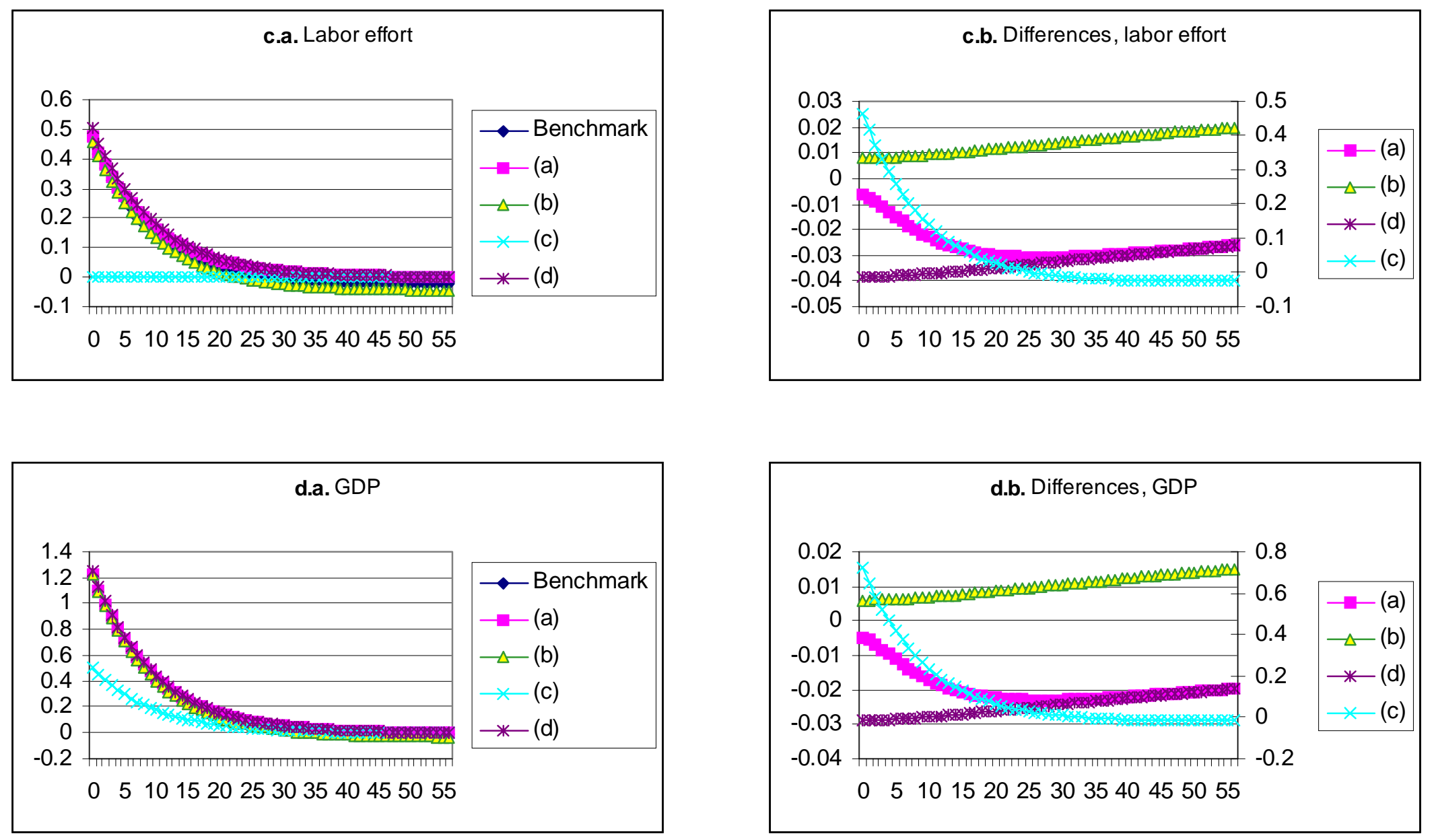
Figure 7. Model comparison, $\phi=.9, \omega^{R}=1,000,000$
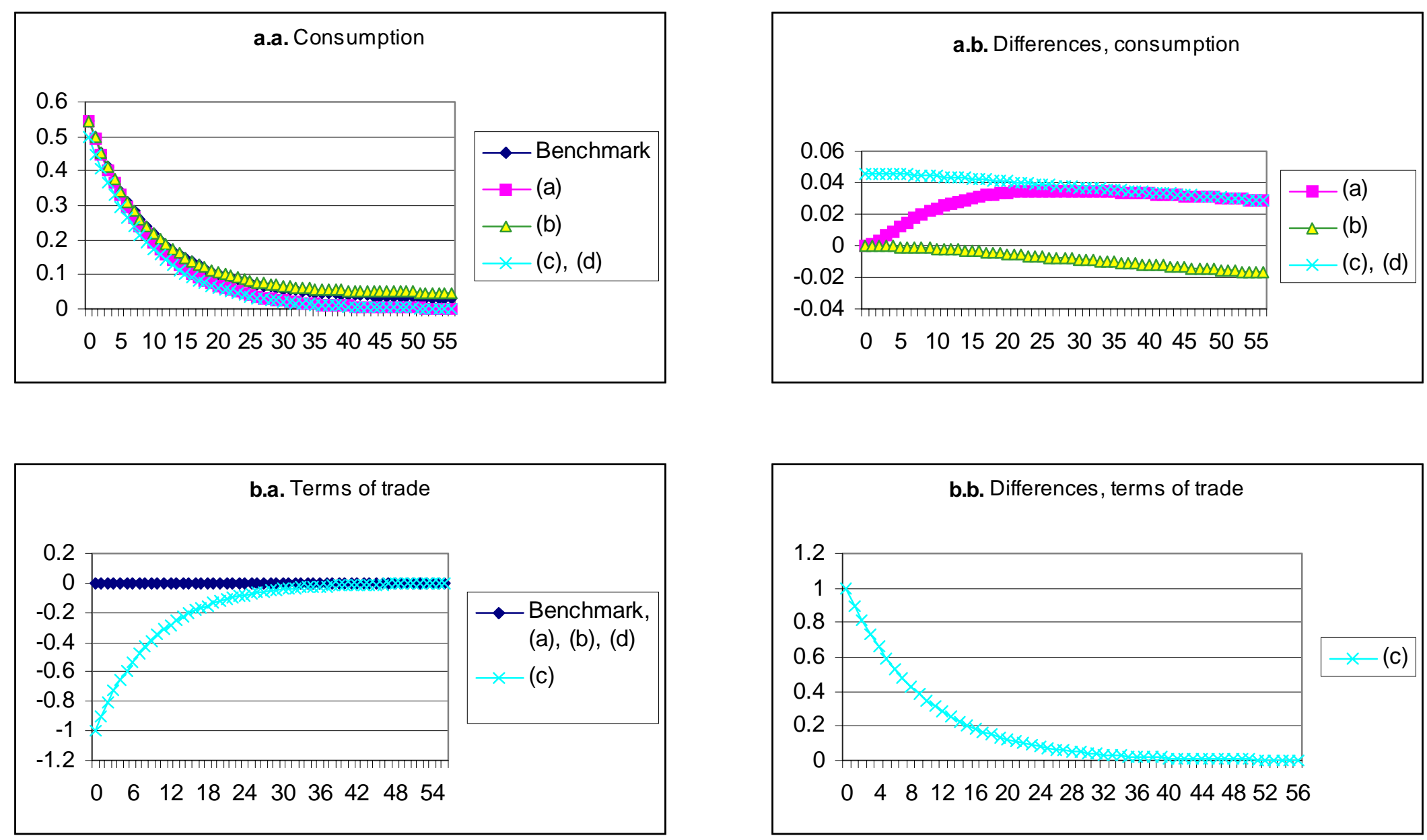
Figure 7, continued
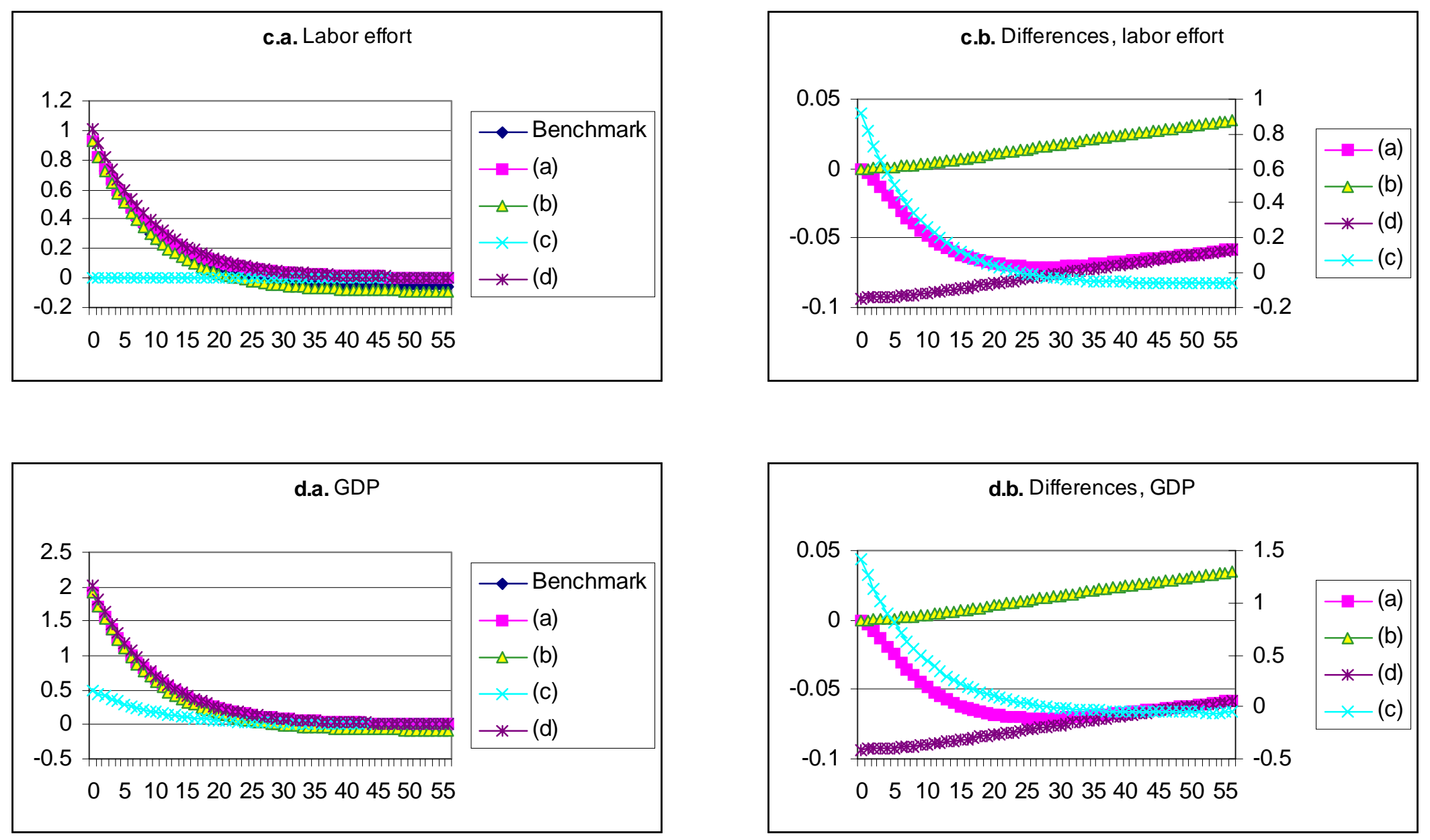
Figure 8. Model comparison, $\phi=1$
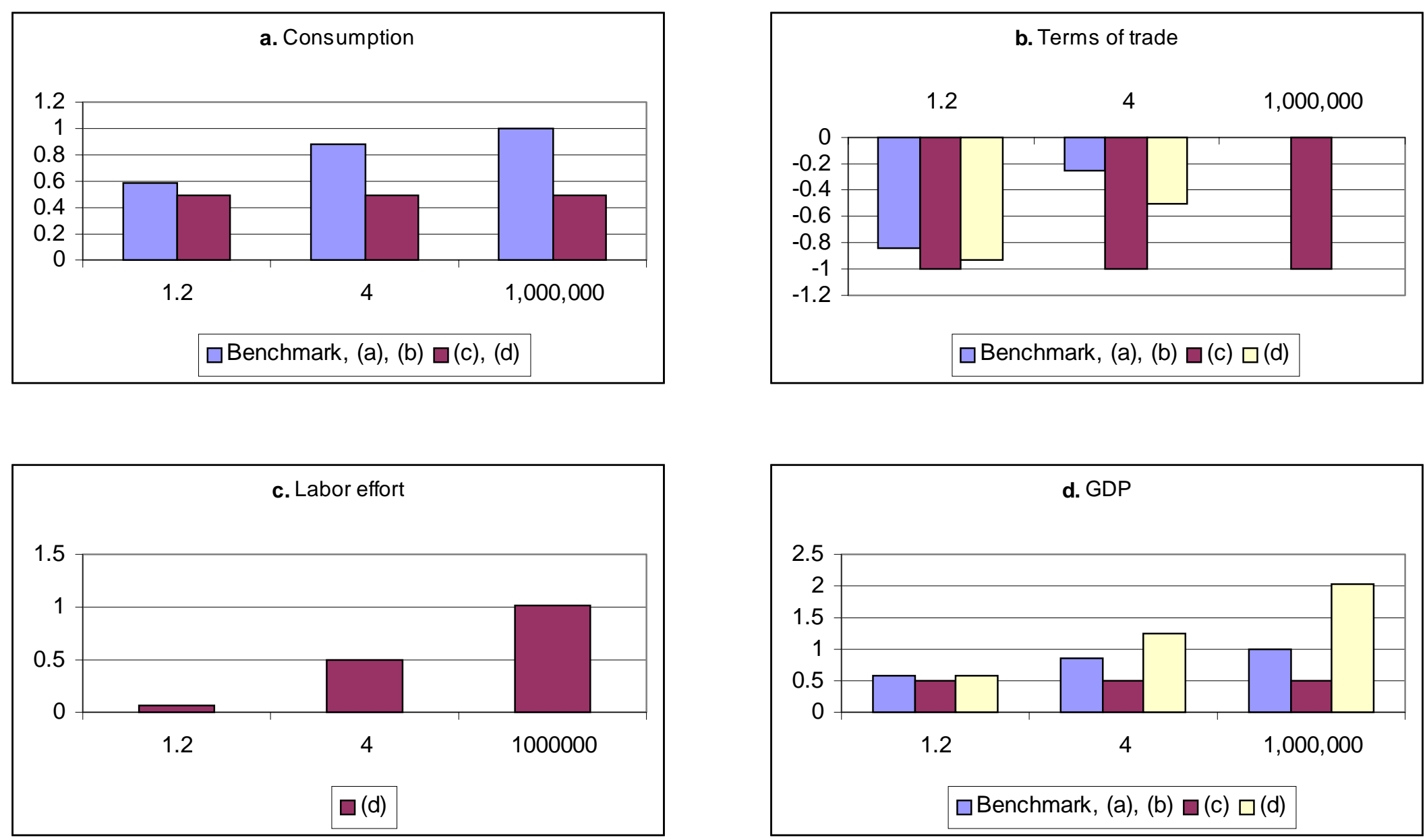
Figure 9. Asymmetric steady state

a. $\phi=0$
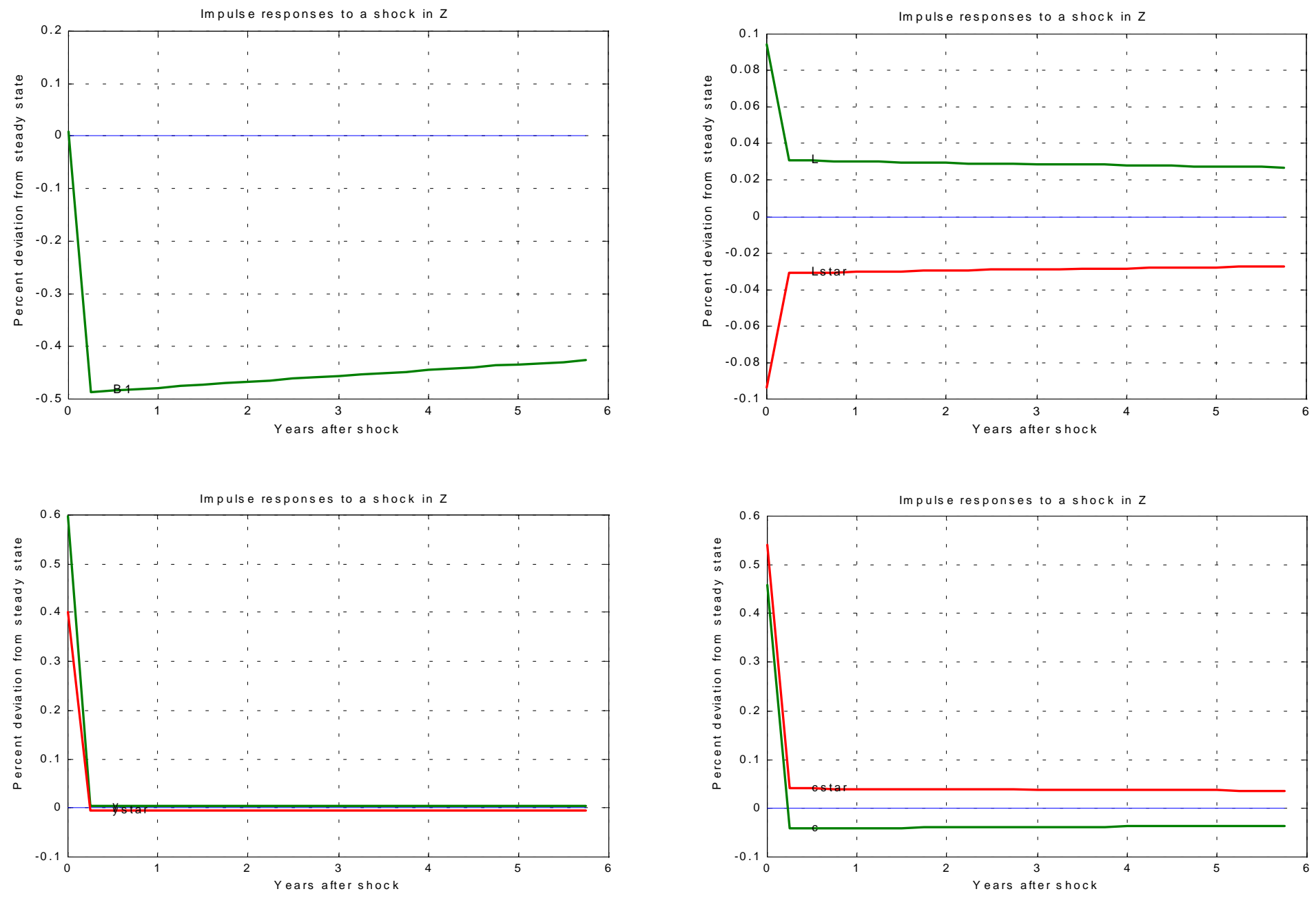
b. $\phi=.9$
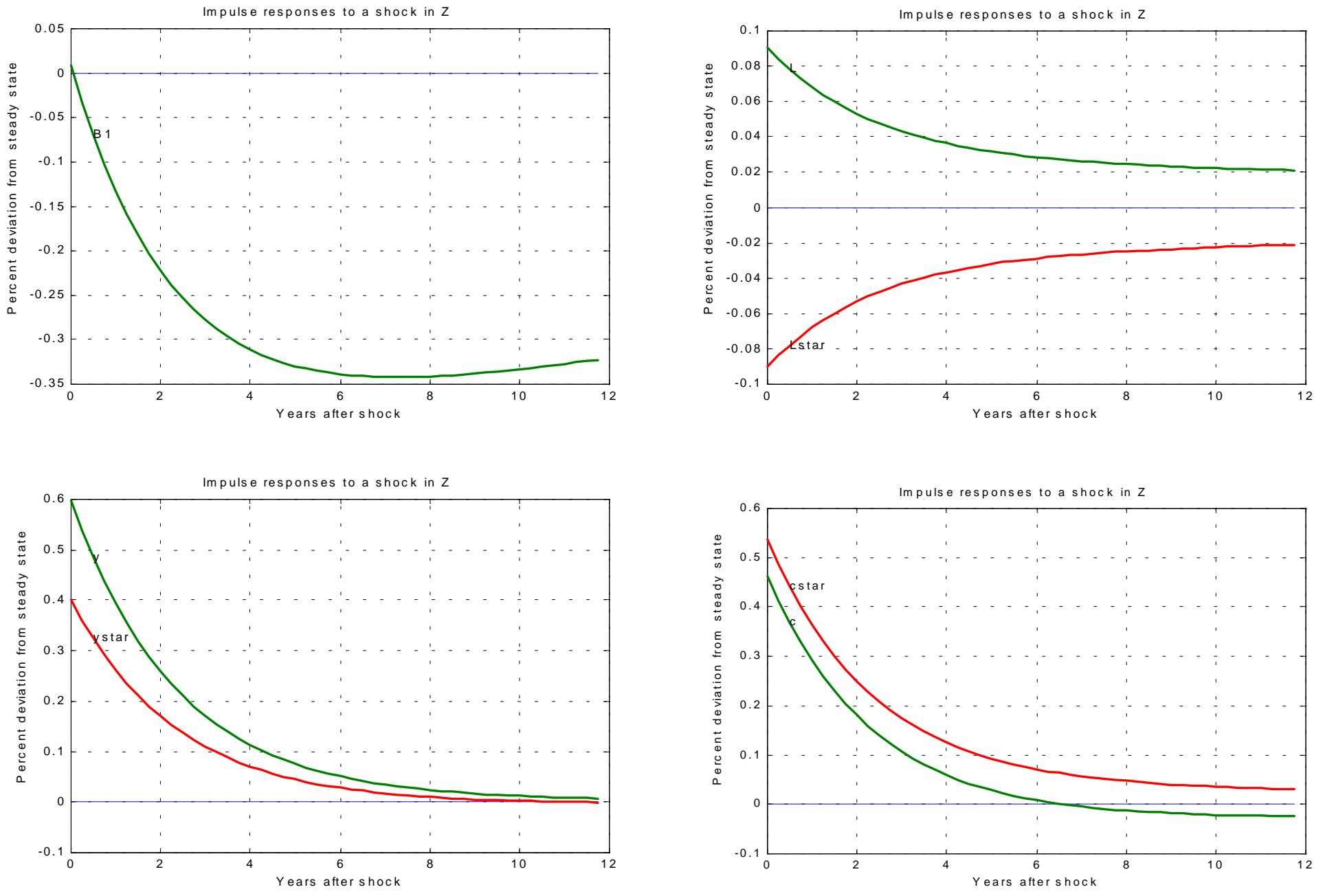